\title{
Applicability of the Maturity Method to High-Performance Concrete
}

Nicholas J. Carino

Lawrence I. Knab

James R. Clifton

Building and Fire Research Laboratory

Gaithersburg, Maryland 20899

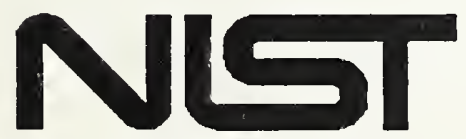

United States Department of Commerce Technology Administration

National Institute of Standards and Technology

QC

100

.056

\#4819

1992 


\section{Applicability of the Maturity Method to High-Performance Concrete}

Nicholas J. Carino

Lawrence I. Knab

James R. Clifton

May 1992

Building and Fire Research Laboratory

National Institute of Standards and Technology

Gaithersburg, MD 20899

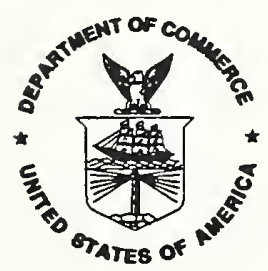

\section{U.S. Department of Commerce}

Barbara Hackman Franklin, Secretary

Technology Administration

Robert M. White, Under Secretary for Technology

National Institute of Standards and Technology

John W. Lyons, Director 



\begin{abstract}
This study examines whether the maturity method is applicable to represent the strength development of high-performance concrete mixtures cured at different temperatures. Two mortar mixtures were investigated having water to cementitious solids ratios of 0.29 and 0.36 . The mixtures were made with Type I cement, silica fume ( $10 \%$ by mass of cement), and a high-range water reducing admixture. Ten batches of mortar were prepared to make cube specimens, which were cured under water at three temperatures: 7,23 , and $40^{\circ} \mathrm{C}$. Compression strengths were measured at ages ranging from 4 hours to 139 days. The strength-age data were analyzed using three models to determine the rate constant for strength development at each curing temperature. The models included two hyperbolic equations (linear and parabolic) and an exponential equation. The rate constant versus curing temperature relationship for each model was represented by a simple exponential equation, which was used to convert test ages to equivalent ages of curing at $23^{\circ} \mathrm{C}$. The strength development of the various mortar batches could be described by a single equation relating relative strength to equivalent age. Thus it was concluded that the maturity method is applicable to describe strength development of the low water-cement ratio mixtures. It was also observed that the estimated long-term strength of the batches did not appear to be affected by the curing temperature. This is in direct contrast with the known behavior of conventional concrete mixtures.
\end{abstract}

Keywords: Concrete, high-performance concrete, curing, maturity method, models, mortar, regression analysis, silica fume, strength, temperature. 


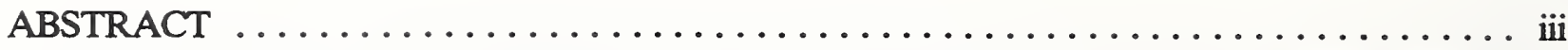

1. INTRODUCTION $\ldots \ldots \ldots \ldots \ldots \ldots \ldots \ldots \ldots \ldots \ldots \ldots \ldots \ldots \ldots \ldots \ldots \ldots$

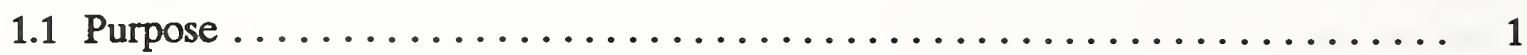

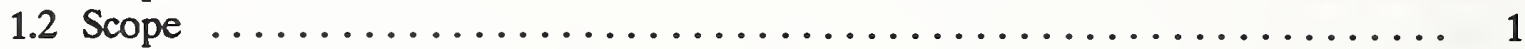

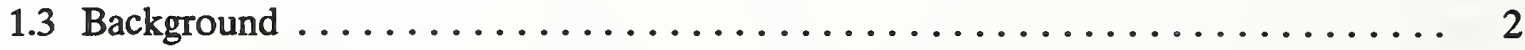

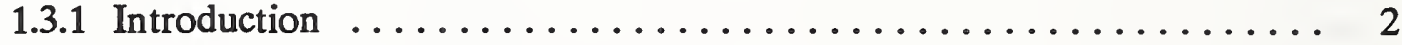

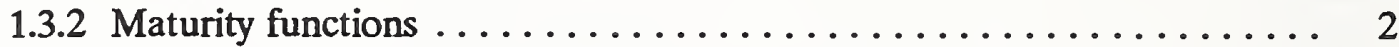

1.3.3 The Arrhenius equation and activation energy ............ 3

1.3.4 Alternative to Arrhenius equation $\ldots \ldots \ldots \ldots \ldots \ldots \ldots \ldots \ldots \ldots \ldots \ldots \ldots$

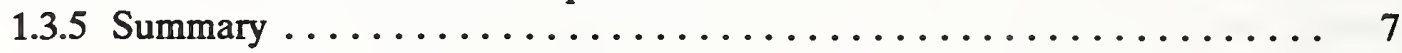

2. EXPERIMENTAL PROGRAM $\ldots \ldots \ldots \ldots \ldots \ldots \ldots \ldots \ldots \ldots \ldots \ldots \ldots \ldots \ldots$

2.1 Materials, Mixture Proportions, and Specimen Preparation $\ldots \ldots \ldots \ldots \ldots 11$

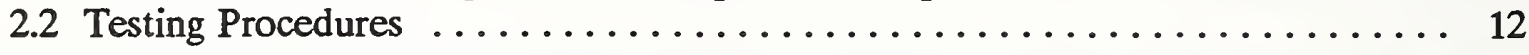

3. TEST DATA AND DATA ANALYSIS $\ldots \ldots \ldots \ldots \ldots \ldots \ldots \ldots \ldots \ldots \ldots \ldots \ldots \ldots \ldots$

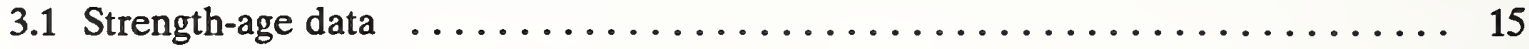

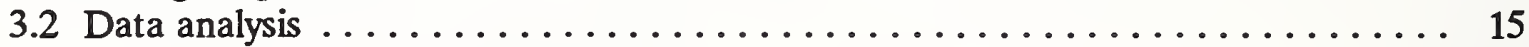

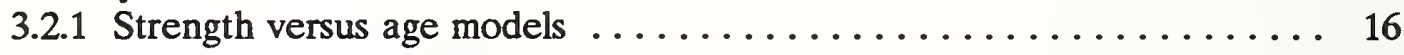

3.2.2 Comparison of strength-age models $\ldots \ldots \ldots \ldots \ldots \ldots \ldots \ldots \ldots$

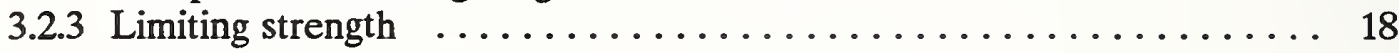

3.2.4 Rate constant versus temperature relationship ............ 20

3.2.5 Relative strength versus equivalent age $\ldots \ldots \ldots \ldots \ldots \ldots \ldots \ldots 21$

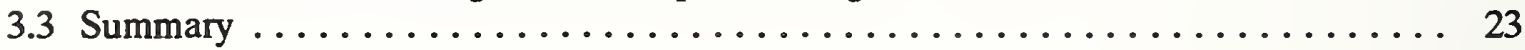

4. CONCLUSIONS AND RECOMMENDATIONS ................. 47

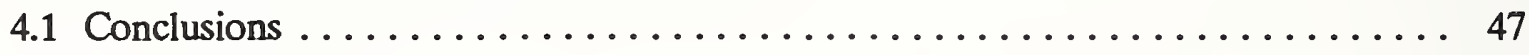

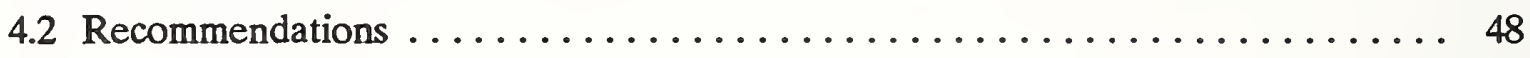

5. ACKNOWLEDGMENTS ................................ 51

6. REFERENCES $\ldots \ldots \ldots \ldots \ldots \ldots \ldots \ldots \ldots \ldots \ldots \ldots \ldots \ldots \ldots \ldots \ldots \ldots \ldots \ldots \ldots \ldots \ldots$

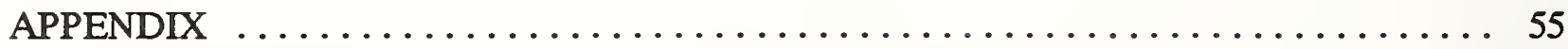

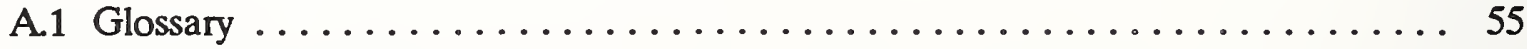

A.2 Strength-Age Data ................................. 57

A.3 Early-Age Temperature Histories ......................... 61 


\subsection{Purpose}

The introduction of high-range water reducing admixtures (superplasticizers) and silica fume has led to a revolution in concrete technology. By using these materials, it is possible to produce workable concrete with extremely low ratios of water to cementitious materials. As a result, the concrete has the potential of developing superior mechanical properties and enhanced durability compared with conventional concrete. Such concrete is an example of a what is known as highperformance concrete.

High-performance concrete can be defined as concrete having desired properties which cannot be obtained by using traditional constituents and traditional production methods (Carino and Clifton 1991). In May 1990, the National Institute of Standards and Technology (NIST) and the American Concrete Institute (ACI) co-sponsored a workshop to develop the outline for a national research plan to enhance the use of this new class of concrete. NIST has embarked on a multi-year research program to address some of the research needs.

Presently, the most widely used type of high-performance concrete is very high-strength concrete, having compressive strength in excess of $55 \mathrm{MPa}(8,000 \mathrm{psi})$. As with conventional concrete, there is a need to be able to monitor the in-place strength gain of very high-strength concrete for safe scheduling of critical construction operations. However, the routine methods for in-place strength evaluation are based on experience with conventional concrete. Thus the NIST/ACI workshop identified in-place testing of high-performance concrete as an important research need.

The maturity method is one of the techniques for estimating the in-place strength gain of conventional concrete. The field procedure is simple; it only involves recording the in-place temperature history. The measured temperature history is used to compute a maturity index, which is used to estimate in-place strength based upon a previously established relationship between strength and the maturity index. NIST has been involved in research to develop a better understanding and standardization of this method (Lew and Reichard 1978, Carino 1984, Tank and Carino 1991, Carino and Tank 1992). However, past studies have dealt with conventional concrete. Thus the purpose of one of the first studies of the NIST high-performance concrete research program was to investigate whether the maturity method is applicable to mixtures having low water-tocementitious materials ratios and incorporating silica fume. The results of this exploratory study are described in this report.

\subsection{Scope}

The objective of this exploratory study was to examine whether the maturity method can be applied to high-performance concrete mixtures. To achieve this objective, the compressive strength gain of mortar cubes cured at three different temperatures $\left(7,23\right.$ and $\left.40{ }^{\circ} \mathrm{C}\right)$ was studied. Two mortar mixtures containing silica fume were used: one had a water-to-cementitious solids ratio of 0.29 and the other had a ratio of 0.36 . Previous work at NIST has shown that testing of mortar will provide the necessary information about the effects of temperature on the strength gain of conventional concrete made with similar cementitious materials (Carino 1984, Tank and Carino 1991, Carino and Tank 1992). 
The remainder of this chapter provides a brief summary of the key aspects of the maturity method. Chapter 2 discusses the experimental procedure. Chapter 3 presents the test results and the results of the analyses. Chapter 4 provides conclusions and recommendations for future studies. The Appendix contains a glossary of the terms used in the report and includes the strength-age data.

\subsection{Background}

\subsubsection{Introduction}

The maturity method was proposed over 40 years ago as means to estimate strength gain under accelerated curing conditions (Nurse 1949, McIntosh 1949, Saul 1951). It was proposed that the temperature history and a maturity function could be used to compute an index that is indicative of the combined effects of time and temperature on strength gain. The maturity rule stated that, provided moisture was available for hydration, samples of the same concrete would have equal strengths if they had equal values of the maturity index irrespective of their actual temperature histories (Saul 1951).

Beginning in the mid 1970s, there was renewed interest in the maturity method, and significant advancements were made, including the development of an ASTM standard for using this technique. Chapter 5 in the handbook by Malhotra and Carino (Malhotra and Carino 1991) summarizes the historical development of the method and provides examples of its application.

The next three sections provide the background information to understand the data analysis procedure in Chapter 3. First, the widely used functions used to calculate a maturity index are reviewed. One of these functions is based on the Arrhenius equation. Since this equation is not widely known by concrete technologists, its origin and its application to concrete maturity are reviewed. The important parameter in the Arrhenius equation is the activation energy, and its significance is discussed. Finally, an alternative to the Arrhenius function is proposed. This alternative function results in a maturity index that produces results which are similar to those obtained by using the Arrhenius equation, but it is simpler in form.

\subsubsection{Maturity functions}

Temperature-Time Factor. One of the earliest, and still widely-used, functions for computing a maturity index has become known as the Nurse-Saul function, and is as follows:

$$
M=\sum_{0}^{t}\left(T_{a}-T_{0}\right) \Delta t
$$

where,

$M \quad=\quad$ maturity index at age $t,{ }^{\circ} \mathrm{C}$-hours or ${ }^{\circ} \mathrm{C}$-days,

$T_{a}=$ average concrete temperature during time interval $\Delta t,{ }^{\circ} \mathrm{C}$, and

$T_{0}=$ datum temperature, ${ }^{\circ} \mathrm{C}$, and

$\Delta t=$ time interval, $\mathrm{h}$ or days.

The index computed by Eq. (1.1) has traditionally been called maturity. However, the current terminology for this index is the temperature-time factor (ASTM C 1074). It can be seen that the temperature-time factor is simply the area between the temperature versus time curve and the datum temperature. Note that only those time intervals during which the temperature exceeds the datum temperature are used in the calculation. In the early work, the datum temperature was taken as the 
temperature at which a cementitious mixtures ceases to gain strength. However, more recent work has shown that this may not necessarily be the best value to use for all cementitious systems (Carino 1984).

Equivalent age: The maturity function given by Eq. (1.1) has won widespread acceptance because of it simplicity, but it has inherent limitations (see, for example, Byfors 1980, Carino 1984). In 1977, Freiesleben Hansen and Pedersen presented an improved function for computing a maturity index. This function converts the measured temperature history of the concrete to an equivalent age of curing at a reference temperature. The equivalent age, $t_{e}$, is defined as follows:

$$
t_{c}=\sum_{0}^{s} e^{-\frac{E}{R}\left(\frac{1}{T_{c}}-\frac{1}{T_{r}}\right)} \Delta t
$$

where,

$t_{\mathrm{e}}=$ the equivalent age at the reference temperature, hours or days

$E=$ "activation energy," $\mathrm{J} / \mathrm{mole}$

$R \quad=\quad$ universal gas constant, $8.314 \mathrm{~J} / \mathrm{K}$-mole,

$T_{a}=\quad$ average absolute temperature of the concrete during time interval $\Delta t,{ }^{\circ} \mathrm{K}$,

$T_{r}=$ absolute reference temperature, ${ }^{\circ} \mathrm{K}$, and

$\Delta t=$ time interval, hours or days.

This maturity function is based on the Arrhenius equation. The derivation of this equation and the meaning of equivalent age are discussed further in the next section. Note that the concrete temperature must be expressed in terms of absolute temperature. The usual value of the reference temperature is the temperature used for standard curing, which is $23^{\circ} \mathrm{C}\left(73^{\circ} \mathrm{F}\right)$ in the ASTM standards. Byfors (Byfors 1980) found that this new maturity function is superior to the Nurse-Saul function, and Carino (Carino 1984) explained why this is so. In this study, the equivalent age at 23 ${ }^{\circ} \mathrm{C}$ is used as the maturity index, but an alternative to Eq. (1.2) is used, as discussed in Section 1.3.4.

\subsubsection{The Arrhenius equation and activation energy}

The key parameter in Eq. (1.2) is the activation energy, $E$, which is a concept that evolved from studies on the effects of temperature on the rate constant of a chemical reaction. In the context of the maturity method, one can consider the rate constant ${ }^{1}$ for strength gain of concrete at a given temperature. Hence the notion of activation energy has been used to describe the effect of temperature on the rate constant for strength gain (Freiesleben Hansen and Pedersen 1977). However, the $E$-value that is determined when the rate constant for strength gain is plotted as a function of the curing temperature is not truly an activation energy as conceived by the originator of the concept.

The idea of activation energy was suggested by Svante Arrhenius in 1888 to explain why chemical reactions do not occur instantaneously when reactants are brought together, even though the reaction products are at a lower energy state (Brown and LeMay 1988). Arrhenius proposed that before the lower energy state can be achieved, the reactants must acquire sufficient energy to overcome an energy barrier separating the unreacted and reacted states. A physical analogy is a brick

${ }^{1}$ The rate constant for strength gain is a parameter in the equation of strength versus age under isothermal curing. The inverse of the rate constant equals the age to attain a certain fraction of the long-term strength (also called the limiting strength). 
standing upright. The brick will not instantaneously tip over to its lower energy state of lying horizontal. It must be pushed from the higher to the lower energy state. The energy required to push the brick from it upright position to the point of instability, after which the brick falls on its own, is the "activation energy" for this process.

For molecular systems, the reactant molecules are in constant motion and energy is transferred between them as they collide (Brown and LeMay 1988). A certain number of molecules will acquire sufficient energy during the collisions to surmount the energy barrier and form the lower energy reaction products. As the system is heated, the kinetic energy of the molecules increases and more of them will surmount the barrier. Hence the rate of reaction increases with increasing temperature. Arrhenius observed that the rate constant, $k$, for many reactions increased with the absolute temperature according to what has since been called the Arrhenius equation, as follows:

$$
k=A e^{-\frac{E}{R T}}
$$

The term $A$ is called the "frequency factor" and is related to the frequency of collisions and the probability that the molecules will be favorable oriented for reaction (Brown and LeMay 1988).

It is now possible to explain the relationship between the Arrhenius equation given by Eq. 1.3 and the equation for equivalent age given by Eq. 1.2. During the curing of a cementitious mixture at a constant temperature, the product of the rate constant, $k$, and age, $t$, determines the relative strength (fraction of the limiting strength) that is obtained at any particular age (see, for example, Eq. (3.1)). Therefore, specimens of the same concrete will have attained the same relative strength if they have equal values of $(k \cdot t)$. The dimensionless quantity $(k \cdot t)$ can be considered as a maturity index. Suppose one sample of concrete is cured at the reference temperature for a length of time equal to $t_{e}$. According to the maturity method, another sample of the same concrete cured under fluctuating temperatures will have developed the same relative strength when the following condition is satisfied:

$$
\begin{aligned}
k_{r} t_{e} & =\sum k_{T} \Delta t \\
t_{e} & =\sum\left(\frac{k_{T}}{k_{r}}\right) \Delta t
\end{aligned}
$$

where,

$k_{r}=$ rate constant at the reference temperature, hours ${ }^{-1}$ or days ${ }^{-1}$,

$k_{T}=$ rate constant at temperature $T$, and

$T=$ average temperature during the time interval $\Delta t$.

If the rate constant is assumed to obey the Arrhenius equation (Eq. (1.3)), the ratio of the value of the rate constant at the curing temperature to the value of the rate constant at the reference temperature is as follows:

$$
\gamma(T)=e^{-\frac{E}{R}\left(\frac{1}{T}-\frac{1}{T_{r}}\right)}
$$

It is seen that Eq. (1.5) is identical to the exponential term in the maturity function used to compute equivalent age according to Eq. (1.2). This exponential term converts increments of actual curing time, $\Delta t$, at the concrete temperature to equivalent increments (in terms of strength gain) at the 
reference temperature. Thus the exponential term can be considered as an age conversion factor, $\gamma(T)$. As an example, if the value of the age conversion factor at a temperature $T\left({ }^{\circ} \mathrm{K}\right)$ were equal to 2.5 , each hour of curing at $T$ would be equivalent to 2.5 hours of curing at the reference temperature, $T_{r}$.

The Arrhenius equation was derived empirically from observations of homogeneous chemical systems undergoing a single reaction. Roy and Idorn (Roy and Idorn 1982) have noted that "...workers... have cautioned that since cement is a multiphase material and also the process of cement hydration is not a simple reaction, homogeneous reaction kinetics cannot be applied." Thus the activation energy obtained from strength gain data is not a true activation energy as originally conceived by Arrhenius. A more appropriate term might be apparent activation energy (Roy and Idorn 1982), which is the term used in the remainder of the report.

In the early 1980 s, a series of studies was initiated at NIST to gain a better understanding of the maturity method (Carino 1982, 1984). From this work, a procedure was developed to obtain the apparent activation energy of a given cementitious mixture (cement, additions, admixtures, and water). The procedure is based on determining the effect of curing temperature on the rate constant for strength gain. As mentioned in footnote 1, the rate constant for strength gain is the reciprocal of the curing time needed to reach a certain fraction ${ }^{2}$ of the limiting strength. The rate constant for a particular curing temperature can be determined by fitting an appropriate equation (see Section 3.2.1) to the strength versus age data acquired under constant temperature (isothermal) curing. The rate constant is one of the parameters in the best-fit equation. The apparent activation energy is determined by fitting the Arrhenius equation to the values of the rate constants plotted as a function of absolute temperature (for details, see Carino 1984).

By using the above procedure, the apparent activation energy was determined for concrete and mortar specimens made with different cementitious materials and admixtures (Tank and Carino 1991, Carino and Tank 1992). It was found that for conventional concrete with a water-cement ratio (W/C) of 0.45 , the apparent activation energy ranged from 30 to $64 \mathrm{~kJ} / \mathrm{mole}$; while for a W/C equal to 0.60 , it ranged from 31 to $56 \mathrm{~kJ} / \mathrm{mole}$. For comparison, Geiker (Geiker 1983) studied the effect of temperature on chemical shrinkage and obtained activation energy values of 61 and $57 \mathrm{~kJ} / \mathrm{mole}$ for mixtures with Type I and Type III cement, respectively.

The significance of the value of the apparent activation energy is demonstrated by observing its effect on the age conversion factor given by Eq. (1.5). Figure 1.1 shows how the age conversion factor varies with curing temperature for different values of the apparent activation energy. The reference temperature is taken as $296^{\circ} \mathrm{K}\left(23^{\circ} \mathrm{C}\right)$. It is seen that for an apparent activation energy of $30 \mathrm{~kJ} / \mathrm{mole}$, the age conversion factor is nearly a linear function of temperature over the range of 0 to $50^{\circ} \mathrm{C}$. In this case, the Nurse-Saul function, Eq. (1.1), would be a reasonably accurate maturity function, because the Nurse-Saul function is equivalent to using an age conversion factor that varies linearly with temperature (Carino 1984, Malhotra and Carino 1991). For an apparent activation energy of $60 \mathrm{~kJ} / \mathrm{mole}$, the age conversion factor is a highly non-linear function of the curing temperature. In this case, the Nurse-Saul function would be an inaccurate maturity function.

The apparent activation energy of a specific concrete must be known to determine the correct age conversion factor and, therefore, the correct equivalent age. Suppose that Eq. (1.2) were used with an apparent activation energy of $45 \mathrm{~kJ} / \mathrm{mole}$, but the actual value for the particular concrete was

${ }^{2}$ The fraction depends on the nature of the strength versus age function as discussed in 3.2.1. 
$60 \mathrm{~kJ} / \mathrm{mole}$. The computed age conversion factor would be higher than its true value for curing temperatures below $23^{\circ} \mathrm{C}$, and it would be lower for temperatures above $23{ }^{\circ} \mathrm{C}$. As a result, the computed equivalent age would be in error; the amount of error would increase for curing temperatures further from $23^{\circ} \mathrm{C}$.

\subsubsection{Alternative to Arrhenius equation}

The authors believe that the Arrhenius equation happens to be one of several empirical equations that can be used to describe the variation of the rate constant for strength gain with curing temperature. This has been the motivation for using a simpler function than Eq. (1.2) to compute equivalent age (Carino 1982, Tank and Carino 1991, Carino and Tank 1992). It is suggested that the temperature dependence of the rate constant for strength gain, $k$, can be represented by the following:

$$
k=A_{0} e^{B T}
$$

where,

$A_{0}=$ the value of the rate constant at $0^{\circ} \mathrm{C}$,

$B=$ temperature sensitivity factor, ${ }^{\circ} \mathrm{C}^{-1}$, and

$T=$ concrete temperature, ${ }^{\circ} \mathrm{C}$.

By using Eqs. (1.5) and (1.6), the equation for equivalent age at the reference temperature $T_{r}$ is as follows:

$$
t_{c}=\sum_{0}^{t} e^{B\left(T-T_{p}\right)} \Delta t
$$

In this case, the age conversion factor, $\gamma(T)$, is as follows:

$$
\gamma(T)=e^{B\left(T-T_{r}\right)}
$$

Equation (1.7) has the following advantages over Eq. (1.2):

- The temperature sensitivity factor, $B$, has more physical significance compared with the apparent activation energy: for each temperature increment of $1 / B$, the rate constant, $k$, increases by a factor of approximately 2.7 .

- Temperatures do not have to be converted to the absolute scale.

- It is a simpler equation.

A numerical study was performed to determine whether Eq. (1.6) can represent the temperature dependence of the rate constant as well as the Arrhenius equation, Eq. (1.3). Values of the rate constant were calculated at different temperatures using the Arrhenius equation (for assumed values of $A$ and $E$ ), and Eq. (1.6) was fitted to those points using the method of least squares. Figure 1.2(a) shows an example of the points for an apparent activation energy of 45 $\mathrm{kJ} / \mathrm{mole}$ and the best-fit exponential curve. It is seen that, over the temperature range considered, Eq. (1.6) provides a good fit to the points. By performing these calculations for different values of apparent activation energy, it was found that there was an approximately proportional relationship between $E$ and $B$ as shown in Fig. 1.2(b). It is concluded that Eqs. (1.2) and (1.7) can be used 
interchangeably, with similar results, to calculate the equivalent age. However, Eq. (1.7) is used in the current study because of its simplicity compared with Eq. (1.2).

\subsubsection{Summary}

The maturity method is a technique to account for the combined effects of time and temperature on the strength gain of a cementitious system, such as concrete. The temperature history and a maturity function are used to compute a maturity index, and strength gain can be related to this index. In this research, the equivalent age at a reference temperature is adopted as the maturity index, and Eq. (1.7) is used as the maturity function. If the maturity method were to be applicable to mixtures with very low ratios of water-to-cementitious solids, it should be possible to convert the strength-gain curves obtained under different curing temperatures to a single curve of strength versus the maturity index. The objective of this exploratory study was to determine whether this was possible.

The approach used to achieve the objective is summarized in Fig. 1.3. Specimens were cured at three different temperatures, and compressive strengths were measured as a function of age. Equations were fitted to the strength-age data, from which the rate constants at the curing temperatures were determined. The rate constants were plotted as a function of the curing temperature and the exponential equation given by Eq. (1.6) was fitted to the data; this established, for each mixture, the temperature sensitivity factor, which describes the change in the value of the rate constant with change in curing temperature. The test ages were converted to equivalent ages using Eq. (1.7), and relative strength was expressed as a function of equivalent age. Implementation of this procedure is discussed in detail in Chapter 3. 


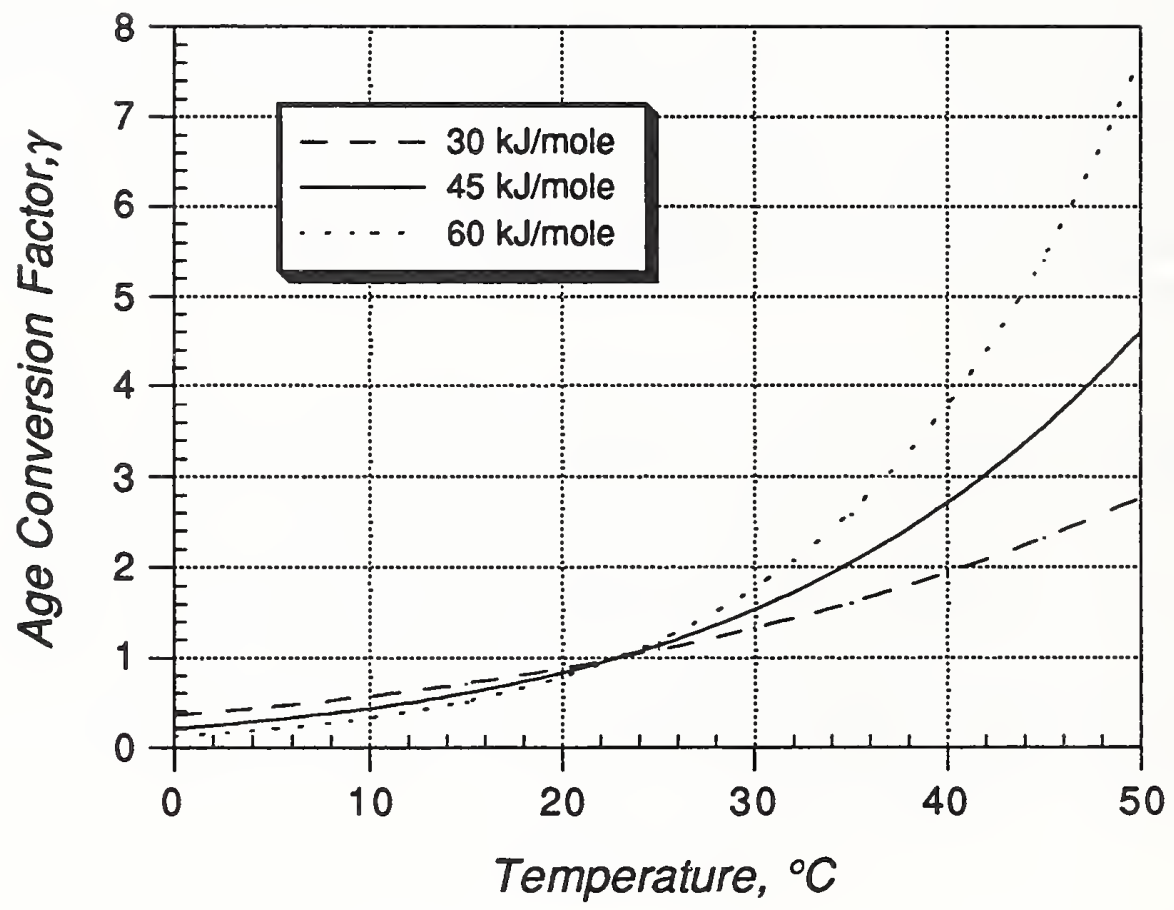

Figure 1.1 Effect of apparent activation energy value on the age conversion factor, Eq. (1.5) 


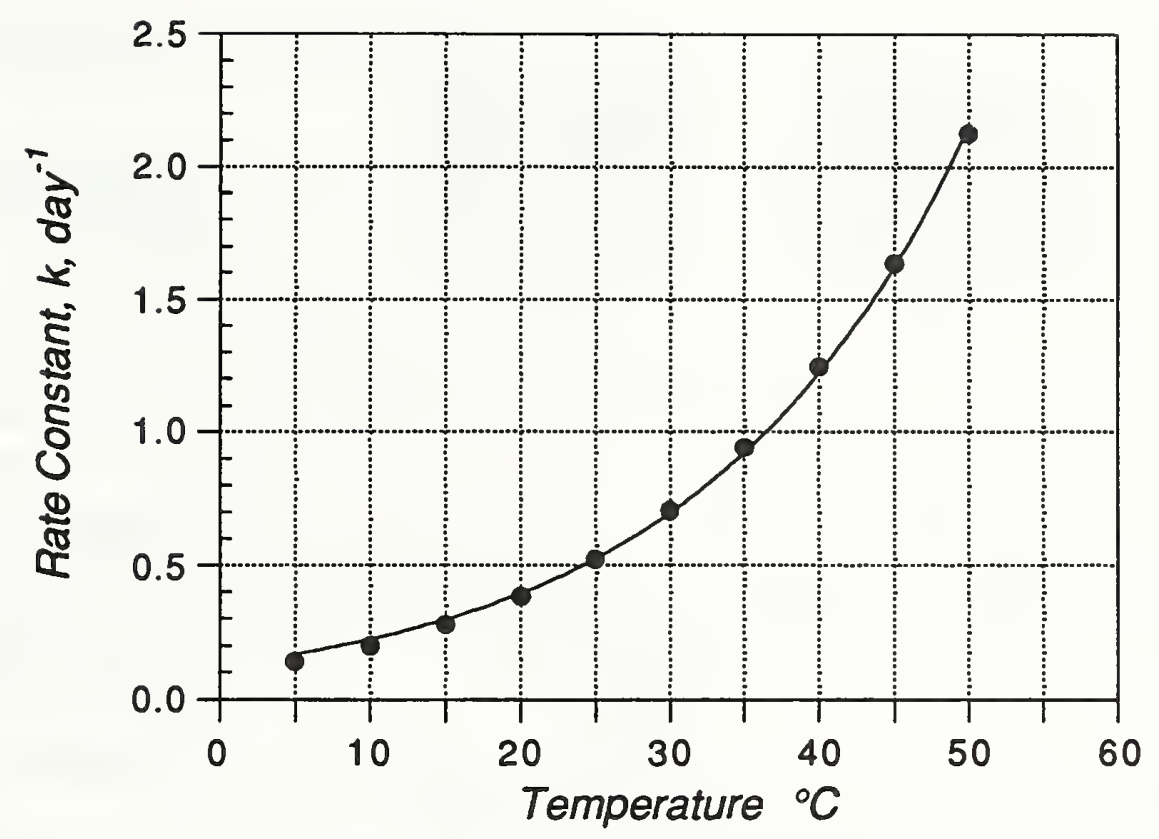

Figure 1.2(a) Example of fit of exponential function, Eq. (1.6), to points which obey the Arrhenius equation, Eq. (1.3)

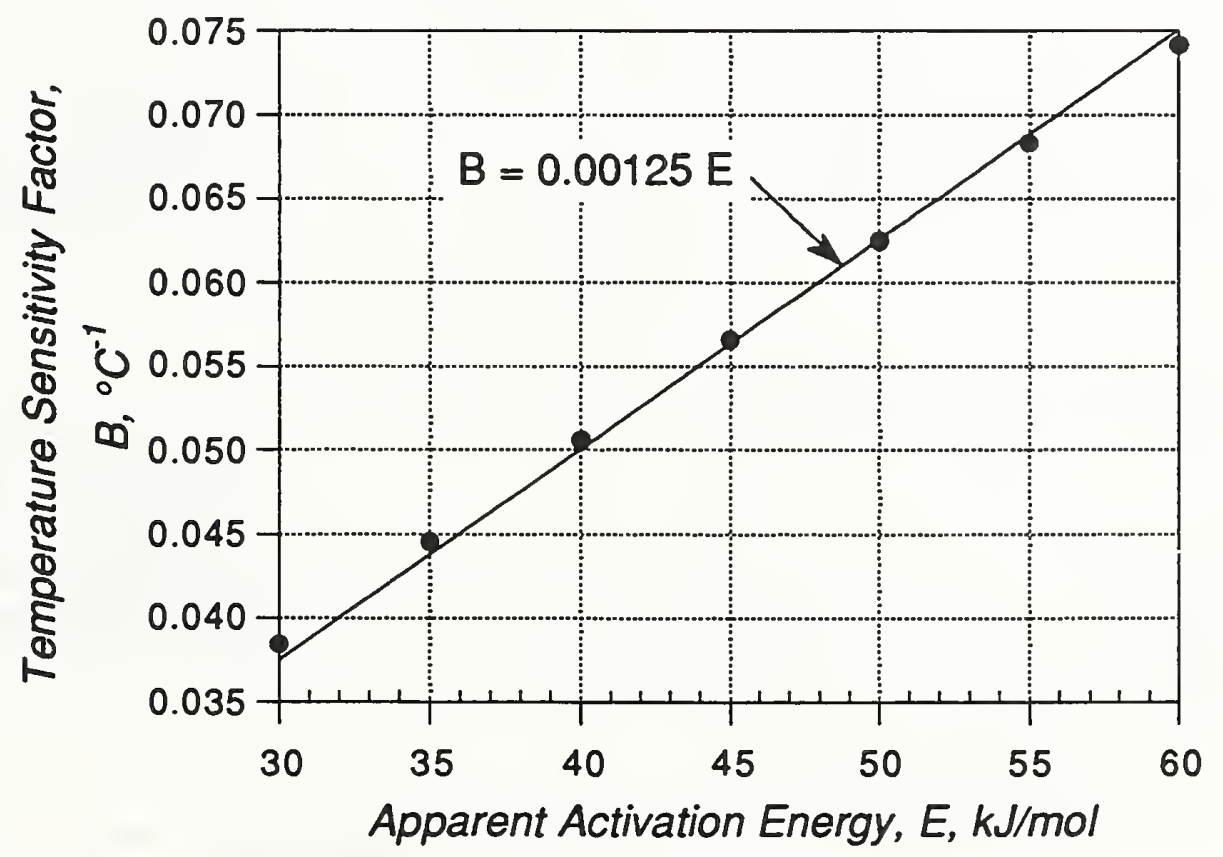

Figure 1.2(b) Relationship between temperature sensitivity factor and apparent activation energy 


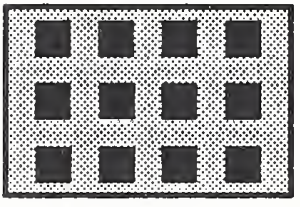

$7 \mathrm{C}$

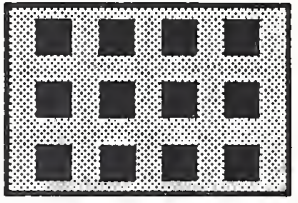

$23 \mathrm{C}$

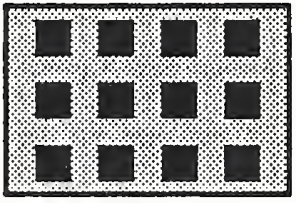

$40 \mathrm{C}$
1. Cure mortar cubes in constant temperature water baths
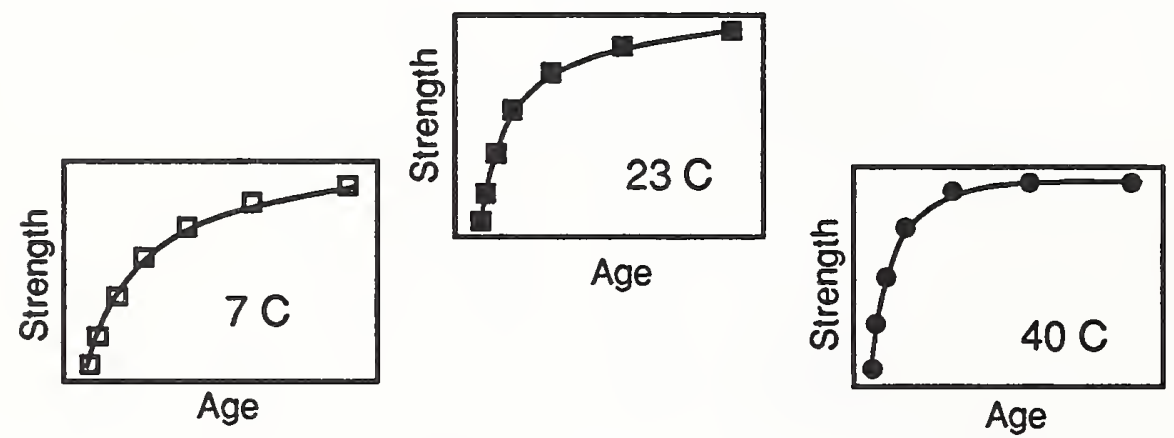

II. For each curing temperature, determine best-fit strength versus age function and rate constant for strength development.

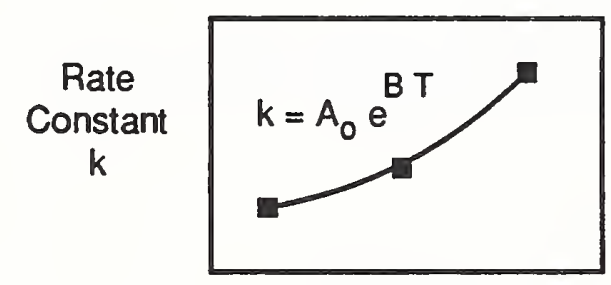

Temperature

III. Determine relationship between rate constant and curing temperature

$$
t_{e}=\sum_{0}^{t} e^{B\left(T-T_{r}\right)} \Delta t
$$

IV. Convert test ages to equivalent ages at $23 \mathrm{C}$ using the maturity function given by Eq. (1.7).

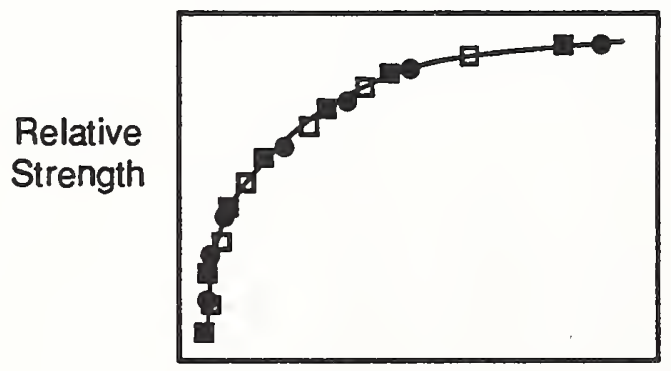

V. Plot relative strength versus equivalent age and determine whether there is a unique curve through the points

Equivalent Age

Figure 1.3 Summary of procedure used to establish applicability of the maturity method 
2.1 Materials, Mixture Proportions, and Specimen Preparation

A Type I portland cement which has been used to produce high-strength concrete in the Chicago area was used; its chemical and physical properties are given in Table 2.1. A commercially available silica fume slurry ${ }^{3,4}$ was used, consisting by mass of 48 percent silica fume solids, 50 percent water, and 2 percent proprietary materials. The liquid slurry was added to provide 10 percent of silica fume solids by mass of cement. The mass of water in the silica fume slurry and the mass of added mix water were combined to determine the water-to-cementitious solids (w/s) ratio. Graded Ottawa sand, meeting the requirements of ASTM C 778, was used. The sand had an absorption of $0.12 \%$. Because the absorption was very low, it was neglected in calculating mixing water requirements. A superplasticizer ${ }^{5}$ was also used. Two water-to-cementitious solids ratios were used: $\mathrm{w} / \mathrm{s}=0.29$ and $\mathrm{w} / \mathrm{s}=0.36$. The mixture proportions are given in Table 2.2.

Prior to mixing each mortar batch, the silica fume slurry was stirred, sieved over a No. 50 sieve, and any lumps retained on the sieve were broken into fine pieces so that the entire mixture passed through the No. 50 sieve. The slurry was blended in a milk-shake type blender prior to use.

A mixer, similar to that specified in ASTM C 305 and having a larger mixing capacity, was used to mix about $3.54 \mathrm{~L}\left(216 \mathrm{in}^{3}\right)$ of mortar, referred to as a "batch" in this report. Each batch yielded twenty-seven, 51-mm (2-in.) cubes. Table 2.3 lists the number, nominal curing temperature, $\mathrm{w} / \mathrm{s}$ ratio, and maximum test age for each of the 10 batches used in the investigation. The initial plan was to have one batch per curing temperature. However, some batches were repeated to resolve questions concerning the strength data that were being obtained.

The ingredients were conditioned until they attained the planned curing temperature $(7,23$, or $40{ }^{\circ} \mathrm{C}$ ) prior to mixing in the laboratory at room temperature. The mixing procedure was essentially that prescribed in ASTM C 305, with minor modifications to accommodate the use of silica fume and the superplasticizer. The silica fume slurry and the distilled water were added into the bowl and then the cement was added to the liquid mixture. After the cement paste had been mixed for $30 \mathrm{sec}$, the sand was added over a $30-\mathrm{sec}$ to $1-\mathrm{min}$ period and the mortar was mixed for $30 \mathrm{sec}$. After the prescribed $1-1 / 2$ min rest period, the superplasticizer was added and the mortar was mixed for 1 $\mathrm{min}$ at low speed, followed by $1 \mathrm{~min}$ at medium speed.

The steel molds were coated with a release agent and were conditioned at the curing temperature. The molds were filled in two layers and consolidated with a small rubber tamper. The

${ }^{3}$ Certain manufacturers' names and names of commercial equipment, instruments, and materials are identified in this report to adequately describe the experimental procedure. Such an identification does not imply recommendation or endorsement by the National Institute of Standards and Technology, nor does it imply that the equipment, instruments, or materials identified are necessarily the best available for the purpose.

4 A silica-fume based liquid admixture, FORCE 10,000, produced by W. R. Grace and Co., Cambridge, Mass.

${ }^{5}$ Daracem-100 superplasticizer complying with ASTM C 494 Type A, F, and G, produced by W. R. Grace and Co., Cambridge, Mass. 
filled molds were covered with plastic plates for protection and were placed immediately in saturated limewater at the curing temperature.

A thermocouple was placed in the center of one cube in each batch to measure its temperature history, and one additional thermocouple was placed in the water bath (not in a cube) to monitor the temperature of the water bath. Just prior to placement in the 7 - and $40-^{\circ} \mathrm{C}$ curing baths, the temperature of the mortar in the molds deviated from the water bath temperature by about 8 to $11{ }^{\circ} \mathrm{C}$. For example, in one batch the mortar was at $32^{\circ} \mathrm{C}$ before being put into the $40^{\circ} \mathrm{C}$ bath; in another batch, the mortar was at $18{ }^{\circ} \mathrm{C}$ before being put into the $7{ }^{\circ} \mathrm{C}$ bath. The cube temperatures reached the bath temperatures within 1 hour after the initial mixing of cement with the water. The temperature histories of each of the batches were recorded by a datalogger connected to a personal computer. Thermocouple data were collected at intervals of 15 minutes or less during the first two days and every 60 minutes thereafter. Figures A.1 through A.4 in the Appendix show the temperatures recorded during the first 48 hours by the thermocouples embedded in the cubes.

After the cubes had hardened sufficiently to resist damage, they were carefully and rapidly stripped from their molds, numbered, and returned to their water baths.

\subsection{Testing Procedures}

Immediately prior to compression testing, the cubes were removed from their water baths and placed in a container with water at or near the bath temperature. Except for several minutes of time required to weigh the cubes prior to testing, the cubes were kept at or near their bath temperature in the container up to the time of testing.

Two hydraulic testing machines were used to measure the compressive strength of the cubes. A $267-\mathrm{kN}$ (60-kip) capacity machine was used to test the cubes at early ages, and a 1.34-MN (300kip) capacity machine was used to test the cubes at later ages. Spherically-seated upper bearing blocks were used and special care was taken to center the cubes to minimize eccentric loading. Load was applied to the cube faces which had been in contact with the plane surfaces of the molds. A load rate of $37 \mathrm{kN} /$ minute ( $8400 \mathrm{lbf} /$ minute) was used except in some cases with older age cubes, where a faster load rate was used during the initial loading up to about one half of the expected maximum load, and then a rate of $37 \mathrm{kN} /$ minute was used for the remainder of the loading.

In each batch and at each temperature, three replicate cubes were tested at each age. Occasionally, when a cube broke at a load substantially different than the other two cubes, a fourth cube was tested and four values were used to compute the average strength.

The test ages of the cubes were planned using data from trial batches coupled with the actual data being collected. Proper test ages were required to provide equally spaced strength intervals, thereby insuring proper distribution of data for meaningful regression analysis. As the data were collected, curves were fitted using both the trial batch and the real data, and the next test age was estimated from the fitted curve. 
Table 2.1(a). Composition of Type I cement ${ }^{+}$

\begin{tabular}{|l|c|l|c|}
\hline Chemical Composition & $\%$ & Chemical Composition & $\%$ \\
\hline Silicon dioxide $\left(\mathrm{SiO}_{2}\right)$ & 20.61 & Tricalcium silicate $\left(\mathrm{C}_{3} \mathrm{~S}\right)$ & 56.0 \\
\hline Aluminum oxide $\left(\mathrm{Al}_{2} \mathrm{O}_{3}\right)$ & 5.21 & Dicalcium silicate $\left(\mathrm{C}_{2} \mathrm{~S}\right)$ & 16.9 \\
\hline Ferric oxide $\left(\mathrm{Fe}_{2} \mathrm{O}_{3}\right)$ & 2.26 & Tricalcium aluminate $\left(\mathrm{C}_{3} \mathrm{~A}\right)$ & 10.0 \\
\hline Calcium oxide $(\mathrm{CaO})$ & 63.50 & Tetracalcium aluminoferrite $\left(\mathrm{C}_{4} \mathrm{AF}\right)$ & 6.9 \\
\hline Magnesium oxide $(\mathrm{MgO})$ & 3.90 & Free-CaO & 0.47 \\
\hline Sulfur trioxide $\left(\mathrm{SO}_{3}\right)$ & 2.72 & Insoluble residue & 0.10 \\
\hline Alkalies as $\left(\mathrm{Na}_{2} \mathrm{O}\right)$ & 0.47 & & \\
\hline Loss on Ignition & 1.27 & & \\
\hline
\end{tabular}

+ Provided by manufacturer

Table 2.1(b). Physical properties of Type I cement ${ }^{+}$

\begin{tabular}{|c|c|}
\hline Physical Test & Result \\
\hline $\begin{array}{l}\text { Fineness, Specific Surface } \\
\text { "Blaine" }\end{array}$ & $3753 \mathrm{~cm}^{2} / \mathrm{g}$ \\
\hline \begin{tabular}{lc}
\multicolumn{2}{l}{ Setting Times } \\
Gillmore: & Initial \\
& Final \\
Vicat: & Initial \\
& Final \\
\end{tabular} & $\begin{array}{l}2 \mathrm{~h} 10 \mathrm{~min} \\
4 \mathrm{~h} 14 \mathrm{~min} \\
1 \mathrm{~h} 21 \mathrm{~min} \\
3 \mathrm{~h} 7 \mathrm{~min}\end{array}$ \\
\hline $\begin{array}{c}\text { Compressive Strength: } \\
1 \text { day } \\
3 \text { day } \\
7 \text { day } \\
28 \text { day }\end{array}$ & $\begin{array}{l}10.6 \mathrm{MPa} \\
22.5 \mathrm{MPa} \\
32.6 \mathrm{MPa} \\
41.7 \mathrm{MPa}\end{array}$ \\
\hline Air Content & $7.9 \%$ \\
\hline False Set & $79.1 \%$ \\
\hline Autoclave Expansion & $0.143 \%$ \\
\hline Finer than \#325 Sieve & $87.6 \%$ \\
\hline
\end{tabular}

+ Provided by manufacturer 
Table 2.2. Mixture proportions of mortars

\begin{tabular}{|c|c|c|c|c|c||}
\hline \hline $\mathrm{w} / \mathrm{s}^{+}$ & $\begin{array}{c}\text { Water } \\
(\mathrm{g})\end{array}$ & $\begin{array}{c}\text { Portland } \\
\text { Cement } \\
(\mathrm{g})\end{array}$ & $\begin{array}{c}\text { Silica Fume } \\
\text { Solids } \\
(\mathrm{g})\end{array}$ & $\begin{array}{c}\text { Super- } \\
\text { plasticizer } \\
(\mathrm{ml})\end{array}$ & $\begin{array}{c}\text { Graded Ottawa } \\
\text { Sand } \\
(\mathrm{g})\end{array}$ \\
\hline 0.29 & 920 & 2920 & 292 & 15 & 4535 \\
\hline 0.36 & 920 & 2315 & 232 & 5 & 5160 \\
\hline
\end{tabular}

${ }^{+}$Water to cementitious solids (mass)

Table 2.3. Curing temperature, water/solids ratio, and maximum test age of cubes for the ten mortar batches

\begin{tabular}{|c|c|c|c|}
\hline Batch No. & $\begin{array}{c}\text { Nominal Curing } \\
\text { Temperature } \\
\left({ }^{\circ} \mathrm{C}\right)\end{array}$ & $\mathrm{w} / \mathrm{s}$ & $\begin{array}{c}\text { Maximum Test } \\
\text { Age, (days) }\end{array}$ \\
\hline 1 & 7 & 0.29 & 139 \\
\hline 2 & 23 & 0.29 & 56 \\
\hline 3 & 23 & 0.29 & 28 \\
\hline 6 & 40 & 0.29 & 14 \\
\hline 6 & 40 & 0.29 & 28 \\
\hline 6 & 7 & 0.36 & 139 \\
\hline 7 & 23 & 0.36 & 56 \\
\hline 8 & 40 & 0.36 & 15 \\
\hline 9 & 40 & 0.36 & 14 \\
\hline 10 & 40 & 0.36 & 28 \\
\hline
\end{tabular}




\subsection{Strength-age data}

Tables A.1 through A.3 in the Appendix summarize the compressive test results for the mortar cubes. The following data are provided in these tables:

- The cumulative average temperature $\left(T_{\text {cum }}\right)$ at the age of testing.

- The age at the time of testing.

- The average and coefficient of variation (CV) of the compressive strength at each test age.

- The average and coefficient of variation of the mass of the cubes at each test age.

The cumulative average temperature was computed as the weighted average temperature from the time of initial mixing until the time of test. As shown in Tables A.1 through A.3, there were small changes in the values of the cumulative average temperature with age. The values for $T_{\text {cum }}$ were not computed at later ages for some of the batches because the data channel was eliminated or it would have been time consuming to reduce all the recorded data. However, all temperature records were examined to verify that the water bath temperatures remained constant for the duration of the tests. In subsequent data analyses, a curing temperature value had to be assigned to each batch. The cumulative average temperature up to the age of the first strength test was used to for this purpose. ${ }^{4}$

The average cube strengths are plotted as a function of age in Fig. 3.1. Logarithmic scales are used for the age axes to accentuate the strength-gain differences due to curing temperature. As expected, the early-age cube strengths increased with the curing temperature. These strength versus age data were analyzed to determine whether there was a suitable maturity function which would transform the actual test ages to equivalent ages at $23^{\circ} \mathrm{C}$ so that strength could be represented as a single-valued function of equivalent age. The methods of analysis and the results are presented in subsequent sections.

\subsection{Data analysis}

Based on previous studies on the application of the maturity method to conventional concrete (Carino 1984, Tank and Carino 1991, Carino and Tank 1992), the following procedure has been developed and is used in this study to analyze strength-age data under constant temperature curing (isothermal) to determine the temperature sensitivity of the rate constant:

- $\quad$ Determine a best-fit, strength-age relationship for each curing temperature.

- Plot the rate constants, obtained from each strength-age relationship, as a function of the curing temperature.

- Determine an empirical relationship between the rate constant and the curing temperature using Eq. (1.6).

${ }^{4}$ For comparison, the cumulative average temperature at the second test age was also used as the curing temperature. The $B$-values describing the temperature dependence of the rate constant (see 3.2.4) were essentially the same, irrespective of which cumulative average temperature was used as the curing temperature. 
Once the rate constant versus temperature relationship is established, the test ages are converted to equivalent ages at a reference temperature, such as $23^{\circ} \mathrm{C}$, using Eq. (1.7).

\subsubsection{Strength versus age models}

The key to developing a suitable maturity function for a particular mixture is to determine the variation of the rate constant with curing temperature. As was discussed in Section 1.3.3, the rate constant is related to the rate of compressive strength gain for isothermal curing, and its value for a particular curing temperature may be obtained from a suitable equation of strength versus age.

In previous work at NIST (Carino 1984, Tank and Carino 1991, Carino and Tank 1992), the following hyperbolic equation has been used successfully to represent strength gain of isothermallycured conventional concrete up to equivalent ages of about 28 days at $23^{\circ} \mathrm{C}$ :

$$
S=S_{u} \frac{k\left(t-t_{0}\right)}{1+k\left(t-t_{0}\right)}
$$

where,

$S=$ strength at age $t, \mathrm{MPa}$,

$S_{u} \quad=\quad$ "limiting" strength, MPa,

$k=$ rate constant, day $^{-1}$, and

$t_{0}=$ age at start of strength development, days.

This equation, which was developed independently by Carino (Carino 1984) and Knudsen (Knudsen 1980) using different approaches, assumes that strength development begins at age $t_{\sigma}$. The gradual strength development during the setting period is not considered. The parameters $S_{u}, k$, and $t_{o}$ are obtained by least-squares curve fitting to strength versus age data. The "limiting" strength, $S_{u}$, is the asymptotic value of the strength for the best-fit hyperbolic function. Quotation marks are used because the best-fit value for $S_{u}$ is not necessarily the true long-term strength of the concrete. This is discussed further in Section 3.2.3. For this hyperbolic model, the rate constant, $k$, has the following characteristic: when the age beyond $t_{0}$ is equal to $1 / k$, the strength equals $50 \%$ of the "limiting" strength, $S_{\mathrm{u}}$. For example if $k=0.4$ day $^{-1}$, the strength will be $0.5 S_{u}$ at an age 2.5 days beyond $t_{\sigma}$

An equation similar to Eq. (3.1) was used by Danish researchers (Knudsen 1980, Geiker 1983) to represent the degree of hydration and the development of chemical shrinkage as a function of age. However, Geiker (Geiker 1983) noted that Eq. (3.1) gave a poor fit for certain cementitious systems. It was found that the following version of the hyperbolic equation fitted that data better than Eq. (3.1) (Geiker 1983, Knudsen 1984):

$$
S=S_{u} \frac{\sqrt{k\left(t-t_{0}\right)}}{1+\sqrt{k\left(t-t_{0}\right)}}
$$

Geiker and Knudsen explained the differences between Eq. (3.1) and Eq. (3.2) in terms of the hydration kinetics of individual cement particles. Equation (3.1) is based on linear kinetics, which means that the degree of hydration of an individual cement particle is related to the product of time and the rate constant. Equation (3.2) is based on parabolic kinetics, which means that the degree of hydration is a function of the square root of the product of time and the rate constant. Thus Eqs. (3.1) and (3.2) will be called the linear-hyperbolic and parabolic-hyperbolic models, respectively. 
Freiesleben Hansen and Pedersen proposed the following exponential equation to represent strength development of concrete (Freiesleben Hansen and Pedersen 1985):

$$
S=S_{u} e^{-\left(\frac{\tau}{t}\right)^{\alpha}}
$$

$\begin{array}{lll}\text { where, } & \\ \alpha \quad= & \text { a time constant, days, and } \\ \alpha & = & \text { a dimensionless shape parameter. }\end{array}$

This equation can model the gradual strength development which occurs during the setting period and it is also asymptotic to a "limiting" strength. It can be shown that the time constant $\tau$ represents the age at which the strength has reached approximately $0.37 S_{u}$. For this exponential equation, the inverse of the time constant is the rate constant for strength development, i.e., $k=1 / \tau$. The shape parameter $\alpha$ affects the slope of the curve during the acceleratory period (following the induction period) and the rate at which the strength approaches the "limiting" strength.

\subsubsection{Comparison of strength-age models}

In this study, all three strength-age models were examined to determine whether one was superior to the others. Commercial software for graphing and data analysis on a personal computer was used to determine the best-fit parameters $\left(S_{u}, k, t_{0}\right.$, etc.) for each of the strength-age models (Abelbeck 1990). The program uses an optimization routine to find the best-fit values of the parameters that minimize the squares of the residuals between the data and the model. The solution procedure is iterative and initial estimates of the values of the parameters are needed as input to the program.

When the parabolic-hyperbolic model, Eq. (3.2), was used, the best-fit values of $t_{0}$ were found to be greater than the first test ages. As a result, the analysis program did not use the first test age for each batch because it would have produced an imaginary number (square root of a negative number). As a consequence, five analyses were performed on the strength-age data for each mortar batch: the linear-hyperbolic and exponential models were fitted to all the data points for each batch, and all three models were fitted without using the data at the earliest test age. The latter types of analyses are identified with the notation " $n-1 . "$ The results of all the regression analyses are summarized in Tables 3.1 and 3.2 for the two w/s values.

In Tables 3.1 and 3.2, the rows labelled "RSD" contain the residual standard deviations of the best-fit equations, and these values are plotted in Fig. 3.2. When all points were used, the linearhyperbolic and exponential models resulted in similar RSD-values. The largest differences occurred in batches \#4 and \#6, and these are illustrated in Fig. 3.3. For Batch \#4, the linear-hyperbolic model gave a better fit than the exponential model, and the opposite was true for Batch \#6. However, these differences are minor as shown by the near coincidence of the best-fit curves in Fig. 3.3.

When the data points at the earliest test ages for each batch were not considered (" $n-1$ " analyses), the following differences were noted:

- For the $w / s=0.29$ mixture, the residual standard deviations (RSD) were: (1) smaller for the linear-hyperbolic and exponential models compared with when all points were used in the 
analyses; (2) larger, on average, for the linear-hyperbolic model; (3) similar, on average, for the exponential and parabolic-hyperbolic models. It can also be seen in Fig. 3.2 that the RSD-values for the parabolic-hyperbolic model were relatively high for the batches cured at $40{ }^{\circ} \mathrm{C}$, but tended to be lower for the batches cured at 7 and $23^{\circ} \mathrm{C}$. As an example, Fig. 3.4 (a) shows the better fit of the parabolic-hyperbolic model compared with the linearhyperbolic model for Batch \# 3 , cured at $23^{\circ} \mathrm{C}$.

For the $w / s=0.36$ mixture, the RSD-values for the linear-hyperbolic and exponential models were similar to those obtained when all data points were considered. Except for the batch cured at $7^{\circ} \mathrm{C}$, the RSD-values for the parabolic-hyperbolic model were the highest. As an example, Fig. 3.4(b) shows the poorer fit of the parabolic-hyperbolic model compared with the linear-hyperbolic model for Batch \#10 cured at $40^{\circ} \mathrm{C}$.

In summary, the analyses of the strength-age data showed that, on the average, the RSDvalues for the linear-hyperbolic and exponential models were similar for all the cases shown in Tables 3.1 and 3.2. On the other hand, the parabolic-hyperbolic model sometimes produced the lowest RSD-values and sometimes produced the highest values. Because none of the models was clearly superior (lowest RSD-value) in all cases, subsequent investigation considered the regression analysis results for all three models: the linear-hyperbolic and exponential models were used with " $n$ " and "n1 " points, while the parabolic-hyperbolic model was used only with "n-1" points.

\subsubsection{Limiting strength}

The strength-age models are similar to each other in that strength approaches a limiting value as age approaches infinity. The value of the "limiting" strength, $S_{u}$, is obtained from least-squares regression analysis (as discussed in Section 3.2.2) of strength data obtained up to a certain age, typically after 28-days of curing at standard temperature $\left(23^{\circ} \mathrm{C}\right)$. However, in this section it will be shown that the computed value of $S_{u}$ is not necessarily the actual long-term strength that would be obtained after a long curing period. The best-fit values of $S_{u}$ for the five analyses of each batch are given in Tables 3.1 and 3.2 and are plotted in Fig. 3.5.

It was anticipated that the "limiting" strength would decrease with increasing curing temperature. This behavior was observed in previous tests at NIST using conventional mortars and concretes cured at different temperatures (Carino 1984, Tank and Carino 1991, Carino and Tank 1992). The detrimental effect of high curing temperature on the actual long-term strength of conventional concrete is well known (ACI 305, 1991). Examination of Fig. 3.5 shows that, for a particular model, the "limiting" strength does not decrease with increasing curing temperature. This is an extremely important finding, because it suggests that the long-term strength of concrete mixtures with very low water-to-cementitious materials ratios may not be as susceptible to the detrimental effects of high curing temperature as are conventional concretes. Additional research is warranted to confirm this finding. If the finding is confirmed, the reason for this behavior should be determined.

Figure 3.5 also shows that there are similarities and differences among the values of $S_{u}$ computed by the various models. When all data points were used, the exponential model in most cases gave slightly larger values than the linear-hyperbolic model. When the first test point was not included in each batch ("n-1" analyses), the following observations may be noted:

- For the linear-hyperbolic model, the values of $S_{u}$ were similar to when all points were considered.

- $\quad$ For most cases, the values of $S_{u}$ for the exponential model were slightly larger than when all points were used. 
The parabolic-hyperbolic model always resulted in the highest value of $S_{u}$ compared with the other models.

Because of the different values of $S_{u}$ obtained by the various analyses, there is the question: Which model results in the most realistic value of the true limiting (or long-term) strength? To examine this question, consider the ratio of the "limiting" strength to the 28-day strength (constant temperature curing) for the three strength-age models. For the hyperbolic models it can be shown that this ratio, $\beta$, is approximately as follows:

$$
\frac{S_{u}}{S_{28}}=\beta \approx 1+\frac{1}{(28 k)^{m}}
$$

where $m=1$ for the linear-hyperbolic model and $m=0.5$ for the parabolic-hyperbolic model. To obtain Eq. (3.4) from Eqs. (3.1) and (3.2), the value of the age of the start of strength development, $t_{o}$, has been neglected because it is small compared with 28 days. Equation (3.4) shows that the value of $\beta$ is related to the rate constant, $k$. A higher value of $k$ results in a lower value of $\beta$, which means a smaller difference between the "limiting" strength and the 28-day strength. To illustrate these relationships, Fig. 3.6(a) shows plots of Eq. (3.4) for various values of the rate constant, $k$. It is seen that the values of $\beta$ are larger for the parabolic-hyperbolic model.

For the hyperbolic models, the value of the rate constant is determined primarily by the initial rate of strength development. Therefore, there is an inherent relationship between the early-age strength development and the value of $\beta$. As the rate of early-age strength development increases (increase in $k$ ), the models predict that the strength gain beyond 28 days decreases.

For the exponential model, the value of $\beta$ is a function of the parameters $\tau$ and $\alpha$ :

$$
\frac{S_{u}}{S_{28}}=\beta=e^{-\left(\frac{\tau}{28}\right)^{\alpha}}
$$

Figure 3.6(b) shows values of $\beta$ for different combinations of $\tau$ and $\alpha$. It is seen that smaller values of $\alpha$ and larger values of $\tau$ result in larger values of $\beta$.

To summarize, the ratios of the "limiting" strength to the 28-day strength are defined by the parameters of the best-fit strength-age equations. For the ranges of parameter values obtained in the present tests, it was found the parabolic-hyperbolic model resulted in the highest values of $\beta$, which means that the parabolic-hyperbolic model predicts higher increases in strength beyond 28 days than the other models.

To determine whether the computed $\beta$-values for the various analyses are plausible, the results from this study are compared with published data shown in Table 3.3. In a study by Carette and Malhotra, strength gain data were obtained for low w/s concrete mixtures made with and without silica fume (Carette and Malhotra 1991). Table 3.3 lists the reported compressive strengths at 28 days and 4 years for standard-cured cylinders. These data show that the 4 -yr strengths were affected little by the presence of silica fume, whereas the 28 -day strengths were consistently higher for the mixtures with $10 \%$ silica fume. As a result, the ratios of 4-yr strength to the 28 -day strength were lower for the silica-fume concretes. Read et al. performed similar work, except that the latest age for strength 
measurement was 2.5 years and silica fume contents were 8 and $12 \%$ (Read et al. 1991). The study by de Larrard and Bostvironnois used concrete with $10 \%$ silica fume and strengths were measured up to 4 years (de Larrard and Bostvironnois 1991). Based on these data, the long-term strengths of silica fume concretes can be expected to be from about 1.15 to 1.3 times the 28-day strengths. Table 3.4 shows the values of $\beta$ obtained in this study by fitting the various strength-age models to the data for the mortar batches cured at $23^{\circ} \mathrm{C}$. The values of $\beta$ corresponding to the exponential and parabolic-hyperbolic models (using " $n-1^{n}$ points) are in reasonable agreement with the strength-ratios shown in Table 3.3. The linear-hyperbolic model and the exponential model, with all points included, resulted in $\beta$ values that were significantly lower than the strength ratios shown in Table 3.3.

In conclusion, this section has examined the significance of the values of $S_{u}$ computed by using the three strength-age models. In the previous section, it was concluded that the linear-hyperbolic and exponential models gave reasonable fits to the measured strength-age data. In this section, however, it was shown that the ratios of $S_{u}$ to the 28-day strengths for the linear-hyperbolic model and the exponential model (using all points) are lower than experimental values obtained after longterm curing. Thus it is concluded that the values of $S_{u}$ computed by fitting the linear-hyperbolic and exponential models to short-term strength-age data should not be considered as true indicators of the long-term, limiting strength. They are simply best-fit parameters for interpolating strength between the test ages used in the analysis. When the earliest test ages were not considered ("n-1" analyses) the exponential and parabolic-hyperbolic models appear to result in values of $S_{u}$ that may be in reasonable agreement with the expected actual long-term strength. The parabolic-hyperbolic model, however, gave the highest values of $S_{u}$ in all cases. Hence these models may be useful for extrapolating the long-term strength based on short-term test data, and additional study of this potential application is warranted.

\subsubsection{Rate constant versus temperature relationship}

As was stated in the introduction of Section 3.2, the relationship between the rate constant and the curing temperature is used to establish the appropriate age conversion factor to transform actual ages at any curing temperature to equivalent ages, in terms of strength gain, at a reference temperature. Figure 3.7 shows the rate constants, reported in Tables 3.1 and 3.2, plotted as a function of the curing temperature. The exponential function given by Eq. (1.6) was used to establish a relationship between the rate constant and curing temperature. The temperature sensitivity factor, $B$, in the exponential function is the parameter that describes the temperature dependence of the rate constant. The resulting best-fit curves are shown in Fig. 3.7. It is seen that the exponential function is a reasonable model for the temperature dependence of the rate constant. As shown in Fig. 3.7(d), the rate constant obtained using the parabolic-hyperbolic model for Batch \#9 (w/s $=0.36$, cured at $40^{\circ} \mathrm{C}$ ) did not agree with the rate constants for the two other batches cured at $40^{\circ} \mathrm{C}$. As a result, that point was not used in determining the $B$-value for $w / s=0.36$ based upon the parabolichyperbolic model.

Table 3.5 gives the $B$-values and their standard errors. For ease of comparison, these $B$-values and their errors are plotted in Fig. 3.8. As discussed in Section 1.3.4, the significance of the $B$-value is a follows: for a temperature increase of $(1 / B){ }^{\circ} \mathrm{C}$, the rate constant, $k$, increases by a factor of 2.7 . Examination of Fig. 3.8 shows that:

- The estimated $B$-values were consistently higher for the $\mathrm{w} / \mathrm{s}=0.36$ mixture, irrespective of the strength-age model that was used to obtain the $k$-values.

- The estimated $B$-values resulting from using the parabolic-hyperbolic strength-age model were larger than from the other models. 
The $B$-values resulting from the linear-hyperbolic and exponential models were slightly higher when the strength-age data for the earliest test age were excluded in the analyses.

Although, these differences in the estimated $B$-values are noted, they are not all statistically significant if the errors of the estimates are considered.

For comparison, Table 3.6 shows the $B$-values obtained in a previous study which examined seven cementitious systems at water-cementitious solids ratios of 0.45 and 0.60 (Carino and Tank 1992). These $B$-values were obtained by fitting the linear-hyperbolic model to strength versus age data for isothermally-cured mortar cubes. Also shown in Table 3.6 are the values of $1 / B$. It is seen that the $B$-values obtained in the present study by using the linear-hyperbolic model fall within the range of the $B$-values obtained previously using the same model with other cementitious systems having ordinary water-to-cementitious solids ratios.

To understand whether the differences in B-values obtained in this study by using the different strength-age models have any practical significance in regard to the application of the maturity method, the test ages were converted to equivalent ages at $23^{\circ} \mathrm{C}$ using the age conversion factor given by Eq. (1.8) and the different $B$-values shown in Table 3.5. Since isothermal curing was used, the age conversion factors for each batch were constant during the curing period. The values of these age conversion factors are shown in Table 3.7. The results are given in the next section.

\subsubsection{Relative strength versus equivalent age}

In the classical maturity method (Saul 1951), it is assumed that for a given mixture of concrete there is a unique relationship between strength and the maturity index. The problem with this assumption is that batch-to-batch variations, such as in initial temperature or water content, can change the long-term strength of a particular batch and result in a different strength-maturity index relationship for that batch. An alternative approach is to use a relative strength versus maturity index relationship, where relative strength refers to strength divided by the "limiting" strength obtained from the regression analyses. This technique has been used successfully at NIST to present strength versus maturity index data in which the strength of various batches were different due to the effects of curing temperature on "limiting" strength (Carino 1984, Tank and Carino 1991, Carino and Tank 1992). This approach was used for the current mortar test data.

Using the "limiting" strength -- The strength versus age data given in Tables A.1 to A.3 in the Appendix were converted to relative strength versus equivalent age values as follows:

- The strength values were divided by the corresponding "limiting" strengths, $S_{u}$, given in Tables 3.1 and 3.2 .

- The test ages were converted to equivalent ages at $23^{\circ} \mathrm{C}$ using the age conversion factors in Table 3.7.

These steps were repeated for each batch and for each of the five models used in the regression analysis of the strength-age data.

The resultant plots of relative strength versus equivalent age for each of the regression analyses models are shown in Figs. 3.9 through 3.13. (Note that Batch \#9 was not included in Fig. 3.12(b) because the data points deviated excessively from those of the other batches.) These figures should be compared with Fig. 3.1, which showed strength as a function of age. It is concluded that the effect of temperature on the strength development of these mortars with very low water-to- 
cementitious-solids ratios can be adequately accounted for by using the maturity method to transform the test ages to equivalent ages at a reference temperature.

Examination of the plotted points in Figs. 3.9 to 3.13 shows that there are different degrees of scatter about a best-fit curve. The fit of the curves obtained by the five methods of regression analysis were examined to determine whether there was a best function to represent the relative strength versus equivalent age relationship. The relative strength and equivalent age values were used to determine the corresponding best-fit relative strength versus equivalent age model. These models are as follows:

$$
\begin{gathered}
\frac{S}{S_{u}}=\frac{\left(\left(k_{r}\left(t_{e}-t_{0_{r}}\right)\right)^{m}\right.}{1+\left(k_{r}\left(t_{e}-t_{0 r}\right)\right)^{m}} \\
\frac{S}{S_{u}}=e^{-\left(\frac{\tau_{r}}{t_{e}}\right)^{e_{r}}}
\end{gathered}
$$

where $t_{e}$ is equivalent age at $23^{\circ} \mathrm{C}$ and the subscript " $\mathrm{r}$ " refers to reference temperature. In Eq. 3.6, values of $m$ equal to 1 and 0.5 correspond to the linear-hyperbolic and parabolic-hyperbolic equations, respectively. These equations are similar to the strength-age models presented in 3.2.1 to model strength development under isothermal conditions. The values of the best-fit parameters and of the residual standard deviations for each model are given in Table 3.8. Also shown in Table 3.8 are the reciprocals of the relative strength values at an equivalent age of 28 days, which are the $\beta$-values given by Eqs. (3.4) and (3.5) that were discussed in 3.2.3.

For ease of comparison, Fig 3.14 shows the residual standard deviations of the various best-fit relationships for relative strength versus equivalent age. First, consider the fit of the linear-hyperbolic and exponential models when all data points are considered. It can be seen that the linear-hyperbolic model resulted in the better fit. This is clearly evident by comparing Fig. 3.9 with Fig. 3.10. The explanation for the poorer performance of the exponential model is straightforward. The equivalent age calculations, given by Eq. (1.7), account only for the effect of temperature on the rate constant, that is, $1 / \tau$. However, the shape of the exponential strength-age function is also affected by the value of the shape factor, $\alpha$. Referring to Tables 3.1 and 3.2, it can be seen that the shape parameters are not the same for the various batches. In Fig. 3.15, the values of the shape parameter are plotted as a function of the curing temperature. With the exception of the results for Batch \#9, it is clear that the shape parameter increases with curing temperature. Further research is needed to develop a technique to account for this temperature dependence in order to have an improved fit of the exponential function.

In the cases where the test data at the earliest ages were not considered ("n-1" analyses), the linear-hyperbolic function also resulted in the best fit of the relative strength versus equivalent age values. For the $w / s=0.29$ mixture, the fit was noticeably improved by not considering the earliest ages in the analyses. Thus, despite the fact that the linear-hyperbolic function did not produce the best fit (i.e., lowest RSD-value) to the strength-age data for each curing temperature (see Fig. 3.2), it was the overall best function for implementing the maturity concept to describe the relative strength development of these high-strength mortar mixtures. 
Using the 28-day strength -- A problem in using the "limiting" strength to compute the relative strength is that a given strength corresponds to a different relative strength depending on the strength-age model that is used. This is because the value of $S_{u}$ obtained from the regression analysis depends on the model. This problem is illustrated by comparing the relative strength values plotted in Fig. 3.11 with those plotted in Fig. 3.12. Because the linear-hyperbolic model results in lower values of the "limiting" strength compared with the parabolic-hyperbolic model, the relative strength values in Fig 3.11 are larger than those in Fig. 3.12. A different transformation can be used to deal with this problem. Instead of expressing relative strength in terms of the "limiting" strength, it can be expressed in terms of the estimated strength at an equivalent age of 28 days. The estimated strength at an equivalent age of 28 days is similar for the various strength-age models because it is obtained by interpolation of the data using a best-fit curve.

To accomplish this transformation, the relative strength data values shown in Figs. 3.9 through 3.11 would be multiplied by the $\beta$-values shown in Table 3.8 (recall that $\beta$ is the ratio of the "limiting" strength, $S_{u}$, to the 28-day strength). Likewise, the best-fit curves shown in Figs. 3.9 through 3.11, which are defined by the parameters in Table 3.8, would also be transformed by multiplying by the $\beta$-values. Because this transformation only represents a change in the scale of the relative strength axis, it does not change the goodness of fit of the transformed curves to the new relative strength values (divided by 28 -day strength). Figure 3.16 shows the resultant relative strength best-fit curves after multiplication by the corresponding $\beta$-values. For clarity, the transformed relative strength data points are not plotted in Fig. 3.16; the "points" which are shown are to distinguish the different transformed curves. Note that all the transformed curves result in similar relative strength values for equivalent ages between about one day and 28 days. All curves have a relative strength value of 1.0 at an equivalent age of 28 days.

\subsection{Summary}

This chapter has summarized the results of the analyses of the strength-age data of two mortar mixtures cured at three different temperatures. First, the data for each were subjected to regression analyses to obtain the best-fit curves of strength versus age. Three different strength-age models were used. None of these models gave the best-fit (lowest RSD-values) to the data in all cases. Thus all three were used in subsequent analyses. After determining the best-fit strength-age curves, the temperature dependencies of the rate constants were evaluated. This permitted conversion of test ages to equivalent ages at $23^{\circ} \mathrm{C}$. Relative strengths were then plotted in terms of equivalent age at $23{ }^{\circ} \mathrm{C}$, and the fit of the various strength-age models was evaluated. Use of the linear-hyperbolic function resulted in the best overall fit to the relative strength versus equivalent age data. Finally, it was shown that it is more meaningful to express relative strength in terms of the strength at an equivalent age of 28 days rather than in terms of the "limiting" strength obtained from the regression analysis. It was shown that the "limiting" strength obtained using the linear-hyperbolic model is not a good estimate of the actual long-term strength. 
Table 3.1 Summary of least-squares regression analysis of strength-age data for $w / s=0.29$

\begin{tabular}{|c|c|c|c|c|c|}
\hline Temperature (C) & 7.7 & 24.2 & 23.5 & 38.8 & 40.0 \\
\hline Batch & $\# 1$ & $\# 2$ & \#3 & \#4 & \#5 \\
\hline \multicolumn{6}{|c|}{ Linear Hyperbolic } \\
\hline $\mathrm{S}_{\mathrm{u}}(\mathrm{MPa})$ & 106.6 & 115.2 & 118.7 & 121.1 & 119.1 \\
\hline$k\left(\right.$ day $\left.^{-1}\right)$ & 0.21 & 0.98 & 0.76 & 2.09 & 1.93 \\
\hline $\mathrm{t}_{0}$ (day) & 0.43 & 0.23 & 0.21 & 0.17 & 0.17 \\
\hline $\mathrm{RSD}(\mathrm{MPa})$ & 5.4 & 7.3 & 6.2 & 2.9 & 4.8 \\
\hline \multicolumn{6}{|c|}{ Exponential } \\
\hline $\mathrm{S}_{\mathrm{u}}(\mathrm{MPa})$ & 117.8 & 121.1 & 128.8 & 120.2 & 119.7 \\
\hline$\tau$ (day) & 3.61 & 0.88 & 1.01 & 0.46 & 0.50 \\
\hline$\alpha$ & 0.62 & 0.75 & 0.70 & 1.03 & 0.97 \\
\hline RSD (MPa) & 4.1 & 6.9 & 5.8 & 4.5 & 5.5 \\
\hline \multicolumn{6}{|c|}{ Linear Hyperbolic (n-1) } \\
\hline $\mathrm{S}_{\mathrm{u}}(\mathrm{MPa})$ & 110.2 & 121.7 & 122.6 & 123.0 & 121.2 \\
\hline$k\left(\right.$ day $\left.^{-1}\right)$ & 0.15 & 0.48 & 0.58 & 1.73 & 1.49 \\
\hline$t_{0}$ (day) & -0.75 & -0.53 & 0.02 & 0.09 & 0.07 \\
\hline RSD (MPa) & 4.7 & 3.2 & 5.4 & 1.4 & 2.9 \\
\hline \multicolumn{6}{|c|}{ Parabolic Hyperbolic (n-1) } \\
\hline $\mathrm{S}_{\mathrm{u}}(\mathrm{MPa})$ & 134.6 & 141.3 & 157.9 & 145.2 & 137.3 \\
\hline$k\left(\right.$ day $\left.^{-1}\right)$ & 0.12 & 0.56 & 0.34 & 1.72 & 2.02 \\
\hline$t_{0}$ (day) & 1.35 & 0.36 & 0.41 & 0.29 & 0.31 \\
\hline RSD & 1.9 & 2.5 & 2.1 & 4.1 & 3.3 \\
\hline \multicolumn{6}{|c|}{ Exponential (n-1) } \\
\hline $\mathrm{S}_{\mathrm{u}}(\mathrm{MPa})$ & 129.2 & 137.5 & 139.9 & 125.0 & 124.3 \\
\hline$\tau$ (day) & 4.02 & 0.94 & 1.22 & 0.44 & 0.47 \\
\hline$\alpha$ & 0.48 & 0.48 & 0.56 & 0.84 & 0.77 \\
\hline $\mathrm{RSD}(\mathrm{MPa})$ & 3.0 & 2.5 & 4.1 & 1.6 & 2.7 \\
\hline
\end{tabular}


Table 3.2 Summary of least-squares regression analysis of strength-age data for $w / s=0.36$

\begin{tabular}{|c|c|c|c|c|c|}
\hline Temperature (C) & 7.3 & 23.9 & 39.5 & 38.2 & 39.8 \\
\hline Batch & \#8 & \#8 & \#8 & \#8 & $\# 10$ \\
\hline \multicolumn{6}{|c|}{ Linear Hyperbolic } \\
\hline $\mathrm{S}_{\mathrm{u}}(\mathrm{MPa})$ & 84.5 & $\cdot 2.3$ & 96.1 & 90.9 & 88.3 \\
\hline$k\left(\right.$ day $\left.^{-1}\right)$ & 0.13 & 0.47 & 1.34 & 1.07 & 1.42 \\
\hline$t_{0}$ (day) & 0.44 & 0.47 & 0.14 & 0.13 & 0.17 \\
\hline $\mathrm{RSD}(\mathrm{MPa})$ & 3.1 & 2.3 & 1.9 & 3.2 & 2.9 \\
\hline \multicolumn{6}{|c|}{ Exponential } \\
\hline $\mathrm{S}_{\mathrm{u}}(\mathrm{MPa})$ & 96.4 & 97.5 & 91.3 & 96.1 & 87.8 \\
\hline$\tau$ (day) & 5.78 & 1.46 & 0.59 & 0.71 & 0.59 \\
\hline$\alpha$ & 0.58 & 0.69 & 0.38 & 0.71 & 0.97 \\
\hline $\mathrm{RSD}(\mathrm{MPa})$ & 2.0 & 2.3 & 2.1 & 3.4 & 3.0 \\
\hline \multicolumn{6}{|c|}{ Linear Hyperbolic (n-1) } \\
\hline $\mathrm{S}_{\mathrm{u}}(\mathrm{MPa})$ & 86.2 & 98.8 & 90.9 & 92.2 & 88.4 \\
\hline $\mathbf{k}\left(\right.$ day $\left.^{-1}\right)$ & 0.11 & 0.42 & 1.27 & 0.91 & 1.41 \\
\hline$t_{0}$ (day) & -0.24 & 0.01 & 0.11 & 0.04 & 0.16 \\
\hline $\mathrm{RSD}(\mathrm{MPa})$ & 2.8 & 1.5 & 2.1 & 2.9 & 3.1 \\
\hline \multicolumn{6}{|c|}{ Parabolic Hyperbolic (n-1) } \\
\hline $\mathrm{S}_{\mathrm{u}}(\mathrm{MPa})$ & 114.4 & 114.6 & 107.4 & 122.3 & 101.8 \\
\hline$k\left(\right.$ day $\left.^{-1}\right)$ & 0.06 & 0.31 & 1.26 & 0.47 & 1.58 \\
\hline$t_{0}$ (day) & 1.60 & 0.58 & 0.37 & 0.28 & 0.36 \\
\hline RSD & 1.0 & 3.8 & 4.0 & 3.7 & 5.2 \\
\hline \multicolumn{6}{|c|}{ Exponential (n-1) } \\
\hline $\mathrm{S}_{\mathrm{u}}(\mathrm{MPa})$ & 101.4 & 98.8 & 92.2 & 100.6 & 88.5 \\
\hline$\tau$ (day) & 6.29 & 1.46 & 0.58 & 0.75 & 0.58 \\
\hline$\alpha$ & 0.51 & 0.66 & 0.82 & 0.65 & 0.92 \\
\hline $\mathrm{RSD}(\mathrm{MPa})$ & 1.6 & 2.1 & 2.4 & 3.0 & 3.2 \\
\hline
\end{tabular}


Table 3.3 Cylinder compressive strength (MPa) at 28 days and later ages

\begin{tabular}{|c|c|c|c|c|c|c|c|}
\hline Reference & Mixture & $w / s$ & 28 day & 2.5 year & 4 year & $S_{2.5 y} / S_{28}$ & $\mathrm{~S}_{4 \mathrm{y}} / \mathrm{S}_{28}$ \\
\hline \multirow{6}{*}{$\begin{array}{c}\text { Carette and } \\
\text { Malhotra } 1991\end{array}$} & Control $^{+}$ & \multirow{2}{*}{0.25} & 66.3 & & 100.3 & & 1.51 \\
\hline & $10 \% \mathrm{SF}$ & & 81.7 & & 107.4 & & 1.31 \\
\hline & Control & \multirow{2}{*}{0.30} & 45.6 & & 69.1 & & 1.52 \\
\hline & $10 \% \mathrm{SF}$ & & 53.2 & & 65.2 & & 1.23 \\
\hline & Control & \multirow{2}{*}{0.40} & 34.4 & & 51.7 & & 1.50 \\
\hline & $10 \% \mathrm{SF}$ & & 42.8 & & 52.7 & & 1.23 \\
\hline \multirow[t]{3}{*}{ Read et al. 1991} & Control $^{+}$ & \multirow{3}{*}{0.27} & 70.1 & 109.4 & & 1.56 & \\
\hline & $8 \% \mathrm{SF}$ & & 81.6 & 96.9 & & 1.19 & \\
\hline & $12 \% \mathrm{SF}$ & & 90.6 & 111.0 & & 1.21 & \\
\hline $\begin{array}{c}\text { de Larrard and } \\
\text { Bostvironnois } \\
1991\end{array}$ & $10 \% \mathrm{SF}$ & 0.24 & 101.1 & & 117.5 & & 1.16 \\
\hline
\end{tabular}

+ Type I cement

Table 3.4 Ratio of "limiting" strength to 28-day strength $\left(S_{u} / S_{28}\right)$ for mortar cubes cured at 23 ${ }^{\circ} \mathrm{C}$ in current study

\begin{tabular}{||c|c|c|c|c|c|c||}
\hline \multicolumn{2}{|c|}{} & \multicolumn{5}{|c||}{ Strength-Age Model } \\
\hline Batch & w/s & Lin-Hyp & Exponential & $\begin{array}{c}\text { Lin-Hyp } \\
\text { (n-1) }\end{array}$ & $\begin{array}{c}\text { Par-Hyp } \\
(\mathrm{n}-1)\end{array}$ & $\begin{array}{c}\text { Exponential } \\
(\mathrm{n}-1)\end{array}$ \\
\hline \hline$\# 2$ & 0.29 & 1.04 & 1.08 & 1.07 & 1.25 & 1.22 \\
\hline$\# 3$ & 0.29 & 1.05 & 1.10 & 1.06 & 1.33 & 1.19 \\
\hline$\# 7$ & 0.36 & 1.08 & 1.14 & 1.09 & 1.34 & 1.15 \\
\hline
\end{tabular}


Table 3.5 Values of the temperature sensitivity factor, $B$, for the various analyses

\begin{tabular}{|c|c|c|}
\hline \multirow{2}{*}{ Model } & \multicolumn{2}{|c|}{$B$-value (error), $\left({ }^{\circ} \mathrm{C}\right)^{-1}$} \\
\cline { 2 - 3 } & $\mathrm{w} / \mathrm{s}=0.29$ & $\mathrm{w} / \mathrm{s}=0.36$ \\
\hline Linear-hyperbolic & $0.057(0.008)$ & $0.071(0.011)$ \\
\hline Exponential & $0.049(0.007)$ & $0.062(0.008)$ \\
\hline Linear-hyperbolic (n-1) & $0.070(0.013)$ & $0.079(0.024)$ \\
\hline Parabolic-hyperbolic (n-1) & $0.092(0.009)^{++}$ & $0.100(0.028)$ \\
\hline Exponential (n-1) & $0.057(0.008)$ & $0.063(0.011)$ \\
\hline
\end{tabular}

$+(n-1)$ refers to analyses in which the data for the earliest test age were not included ${ }^{++}$Rate constant for Batch \#9 not included in analysis

Table 3.6 Temperature sensitivity factors, $B$, for mortar mixtures obtained by using the linearhyperbolic strength-age model (Carino and Tank 1992)

\begin{tabular}{||c|c|c|c|c|}
\hline & \multicolumn{2}{|c|}{$\mathrm{W} / \mathrm{C}=0.45$} & \multicolumn{2}{c|}{$\mathrm{W} / \mathrm{C}=0.60$} \\
\hline $\begin{array}{c}\text { Cementitious } \\
\text { System }\end{array}$ & $\begin{array}{c}B \text {-value } \\
{ }^{\circ} \mathrm{C}^{-1}\end{array}$ & $\begin{array}{c}1 / B \\
{ }^{\circ} \mathrm{C}\end{array}$ & $\begin{array}{c}B \text {-value } \\
{ }^{\circ} \mathrm{C}^{-1}\end{array}$ & $\begin{array}{c}1 / B \\
{ }^{\circ} \mathrm{C}\end{array}$ \\
\hline Type I & 0.082 & 12.2 & 0.058 & 17.2 \\
\hline Type II & 0.075 & 13.3 & 0.058 & 18.2 \\
\hline Type III & 0.054 & 18.5 & 0.057 & 17.5 \\
\hline Type + Fly ash & 0.044 & 22.7 & 0.049 & 20.4 \\
\hline Type I + Slag & 0.057 & 18.5 & 0.069 & 17.5 \\
\hline Type I + Accelerator & 0.073 & 13.7 & 0.070 & 14.3 \\
\hline Type I + Retarder & 0.056 & 17.9 & 0.046 & 21.7 \\
\hline
\end{tabular}


Table 3.7 Age conversion factors to calculate equivalent ages at $23{ }^{\circ} \mathrm{C}$

\begin{tabular}{|c|c|c|c|c|c|c|}
\hline \multicolumn{2}{|c|}{} & \multicolumn{6}{|c|}{ Age Conversion Factor, $\gamma(T)$} \\
\hline Batch & $\mathrm{T}_{\text {cum }}{ }^{+}$ & Lin-Hyp & Exp & $\begin{array}{c}\text { Lin-Hyp } \\
(\mathrm{n}-1)\end{array}$ & $\begin{array}{c}\text { Par-Hyp } \\
(\mathrm{n}-1)\end{array}$ & $\begin{array}{c}\text { Exp } \\
(\mathrm{n}-1)\end{array}$ \\
\hline$\# 1$ & 7.7 & 0.42 & 0.48 & 0.34 & 0.21 & 0.42 \\
\hline$\# 8$ & 24.2 & 1.07 & 1.06 & 1.09 & 1.12 & 1.07 \\
\hline$\# 3$ & 23.5 & 1.03 & 1.02 & 1.04 & 1.05 & 1.03 \\
\hline$\# 8$ & 39.6 & 2.44 & 2.16 & 3.00 & 4.29 & 2.46 \\
\hline$\# 8$ & 40.0 & 2.61 & 2.28 & 3.26 & 4.79 & 2.64 \\
\hline$\# 8$ & 7.3 & 0.33 & 0.38 & 0.29 & 0.21 & 0.37 \\
\hline$\# 7$ & 23.9 & 1.07 & 1.06 & 1.07 & 1.09 & 1.06 \\
\hline$\# 8$ & 39.6 & 3.23 & 2.78 & 3.68 & 5.18 & 2.85 \\
\hline$\# 8$ & 38.2 & 2.94 & 2.57 & 3.32 & 4.55 & 2.62 \\
\hline$\# 10$ & 39.8 & 3.30 & 2.83 & 3.76 & 5.34 & 2.90 \\
\hline
\end{tabular}

${ }^{+}$The cumulative average temperature at the age of the first strength test 
Table 3.8 Summary of least-squares regression analysis of relative strength versus equivalent age

\begin{tabular}{|c|c|c|}
\hline & $\mathrm{w} / \mathrm{s}=0.29$ & $\mathrm{w} / \mathrm{s}=0.36$ \\
\hline \multicolumn{3}{|c|}{ Linear Hyperbolic } \\
\hline $\mathrm{k}_{\mathrm{r}}\left(\right.$ day $\left.^{-1}\right)$ & 0.71 & 0.40 \\
\hline$t_{0 r}$ (day) & 0.27 & 0.28 \\
\hline RSD & 0.053 & 0.038 \\
\hline$\beta^{*}$ & 1.05 & 1.09 \\
\hline \multicolumn{3}{|c|}{ Exponential } \\
\hline$\tau_{\mathrm{r}}$ (day) & 1.13 & 1.75 \\
\hline$\alpha_{r}$ & 0.77 & 1.79 \\
\hline RSD & 0.070 & $0.05 \pi$ \\
\hline$\beta$ & 1.09 & 1.11 \\
\hline \multicolumn{3}{|c|}{ Linear Hyperbolic (n-1) } \\
\hline $\mathrm{k}_{\mathrm{r}}\left(\right.$ day $\left.^{-1}\right)$ & 0.48 & 0.32 \\
\hline $\mathrm{t}_{0 \mathrm{r}}$ (day) & -0.15 & -0.03 \\
\hline RSD & 0.036 & 0.041 \\
\hline$\beta$ & 1.07 & 1.11 \\
\hline \multicolumn{3}{|c|}{ Parabolic Hyperbolic (n-1) } \\
\hline $\mathrm{k}_{\mathrm{T}}\left(\right.$ day $\left.^{-1}\right)$ & 0.36 & 0.21 \\
\hline $\mathrm{t}_{0 \mathrm{r}}$ (day) & 0.37 & 0.36 \\
\hline RSD & 0.046 & 0.057 \\
\hline$\beta$ & 1.32 & 1.11 \\
\hline \multicolumn{3}{|c|}{ Exponential (n-1) } \\
\hline$\tau_{\mathrm{r}}$ (day) & 1.19 & 1.79 \\
\hline$\alpha_{r}$ & 0.59 & 0.68 \\
\hline RSD & 0.062 & 0.058 \\
\hline$\beta$ & 1.17 & 1.17 \\
\hline
\end{tabular}

* $\beta=$ Ratio of the limiting strength, $S_{u}$, to the 28 -day strength 

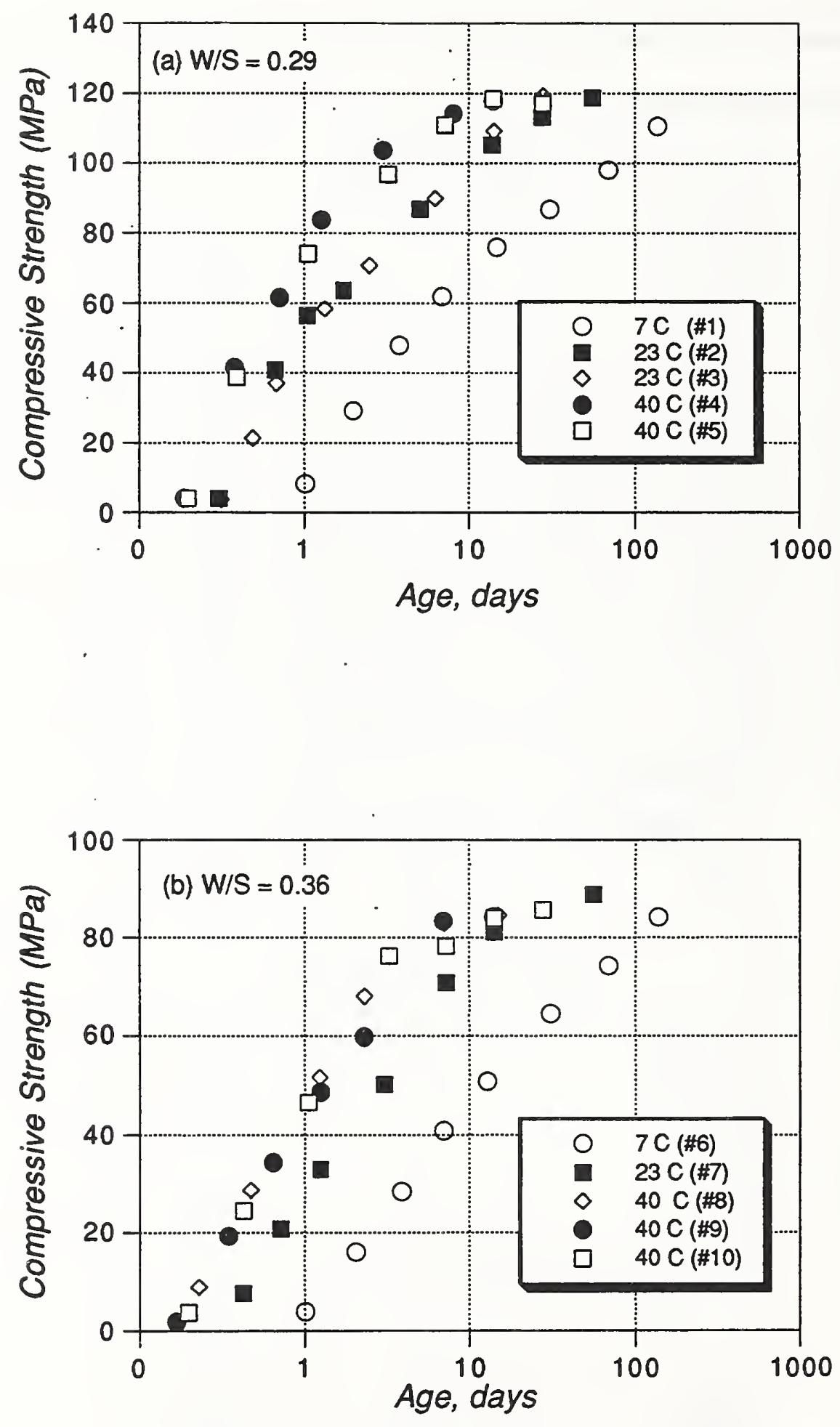

Figure 3.1 Average cube strength versus age: (a) W/S $=0.29$ and (b) $W / S=0.36$ 

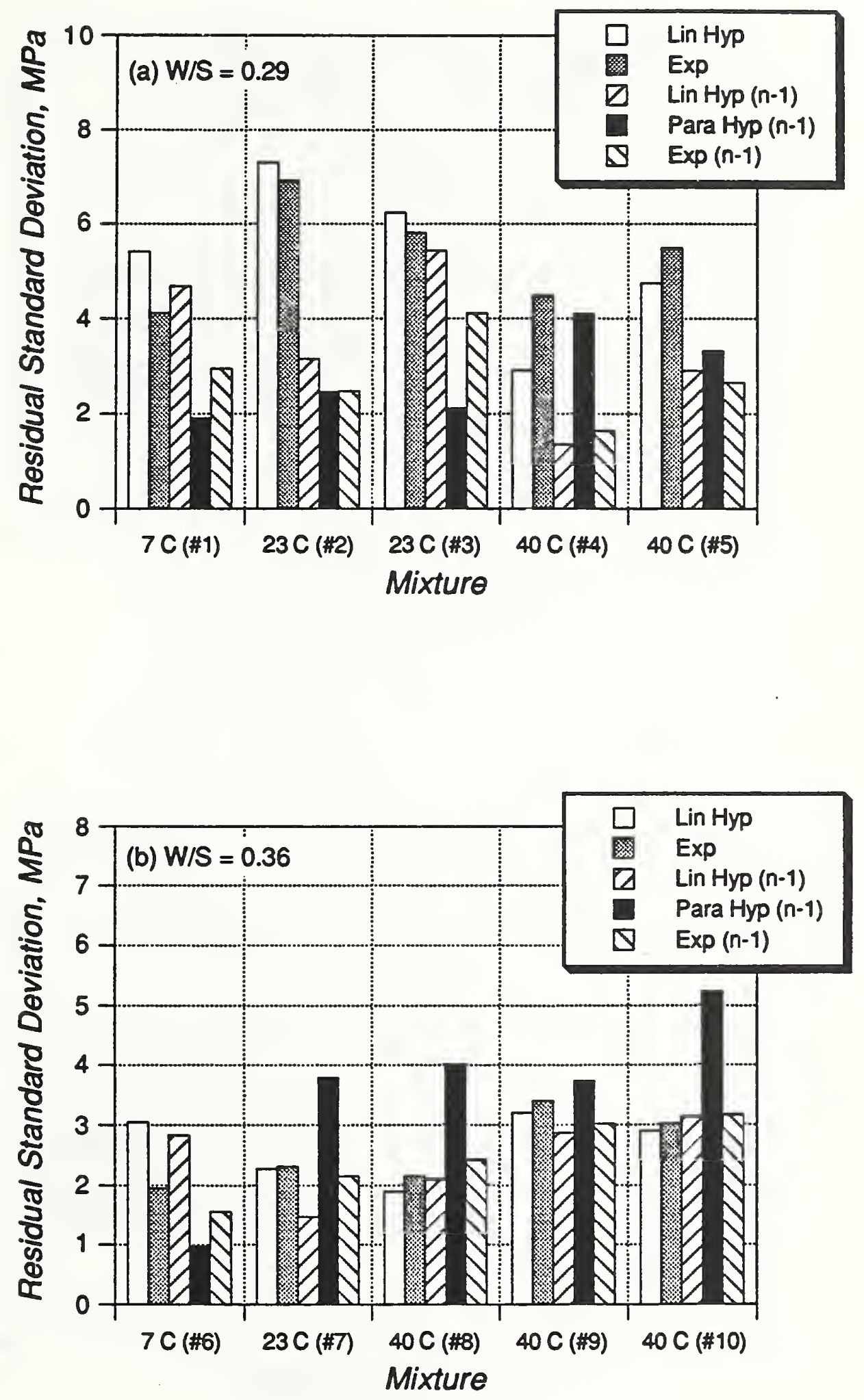

Figure 3.2 Residual standard deviation of best-fit strength-age models: (a) W/S $=0.29$ and (b) $\mathrm{W} / \mathrm{S}=0.36$ 

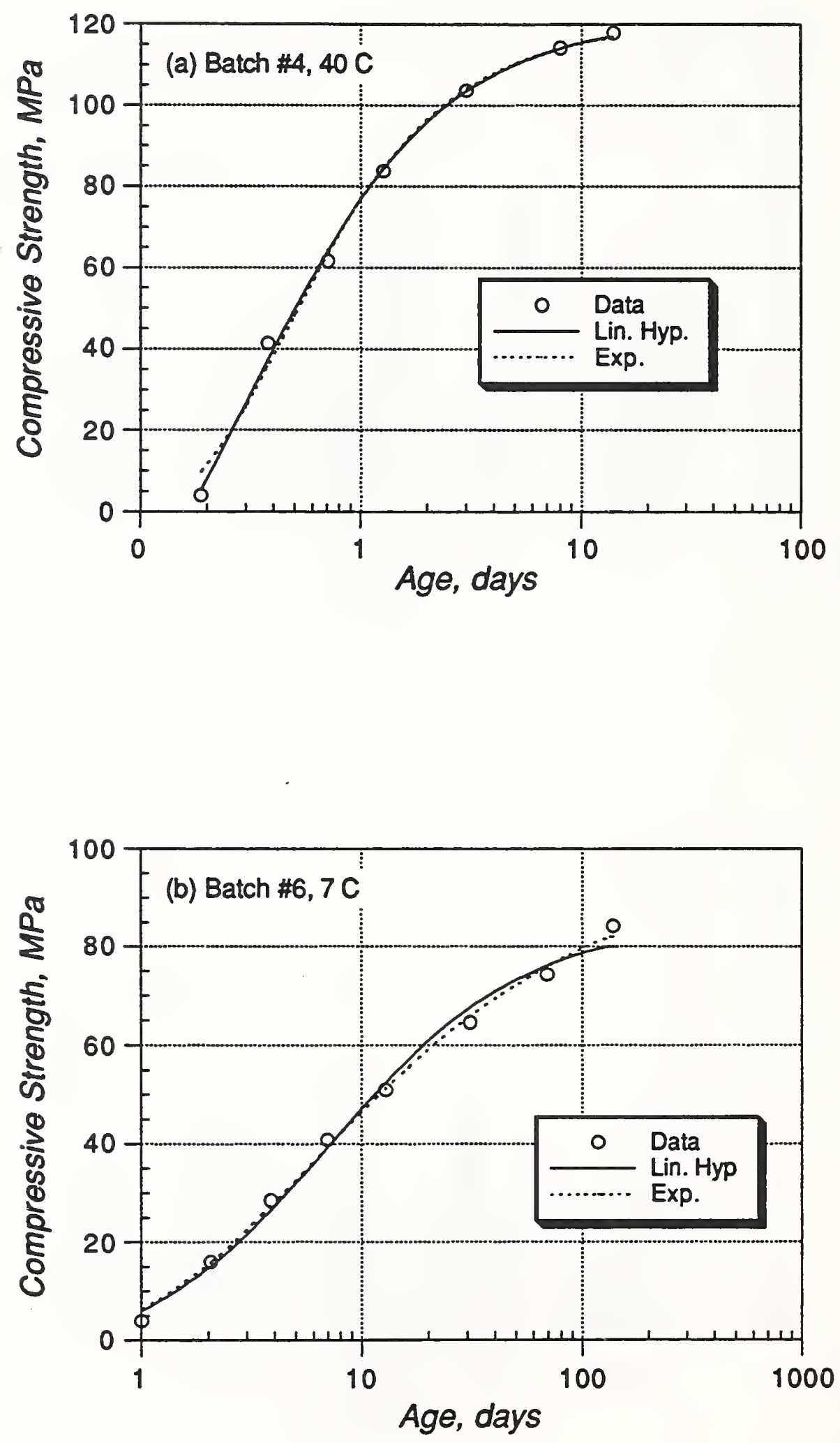

Figure 3.3 Comparison of linear-hyperbolic and exponential strength-age models (all points included) 

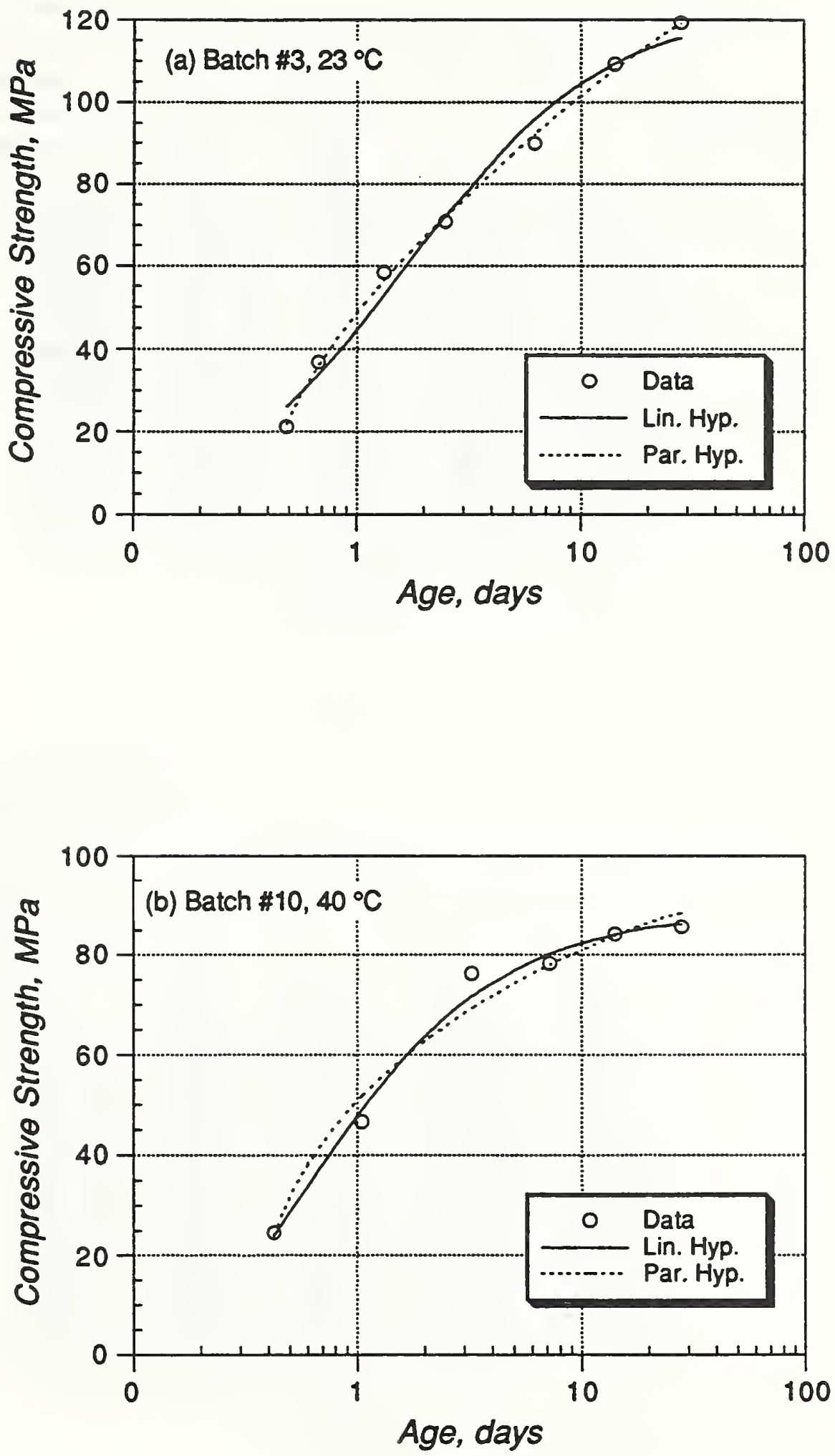

Figure 3.4 Comparison of linear-hyperbolic and parabolic-hyperbolic strength-age models (earliest test age not included) 

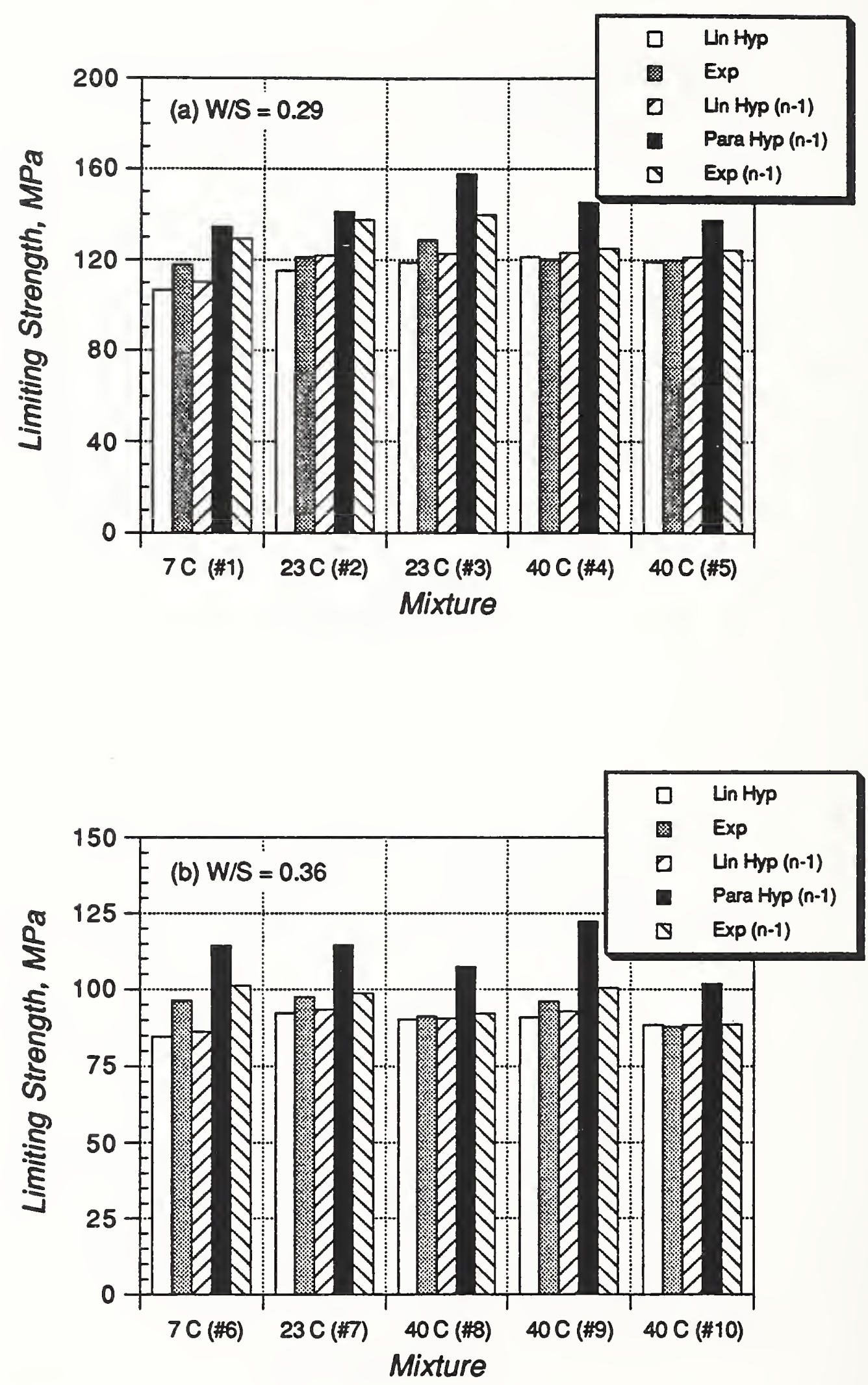

Figure 3.5 Limiting strength values obtained by the various analyses of the strength-age data 

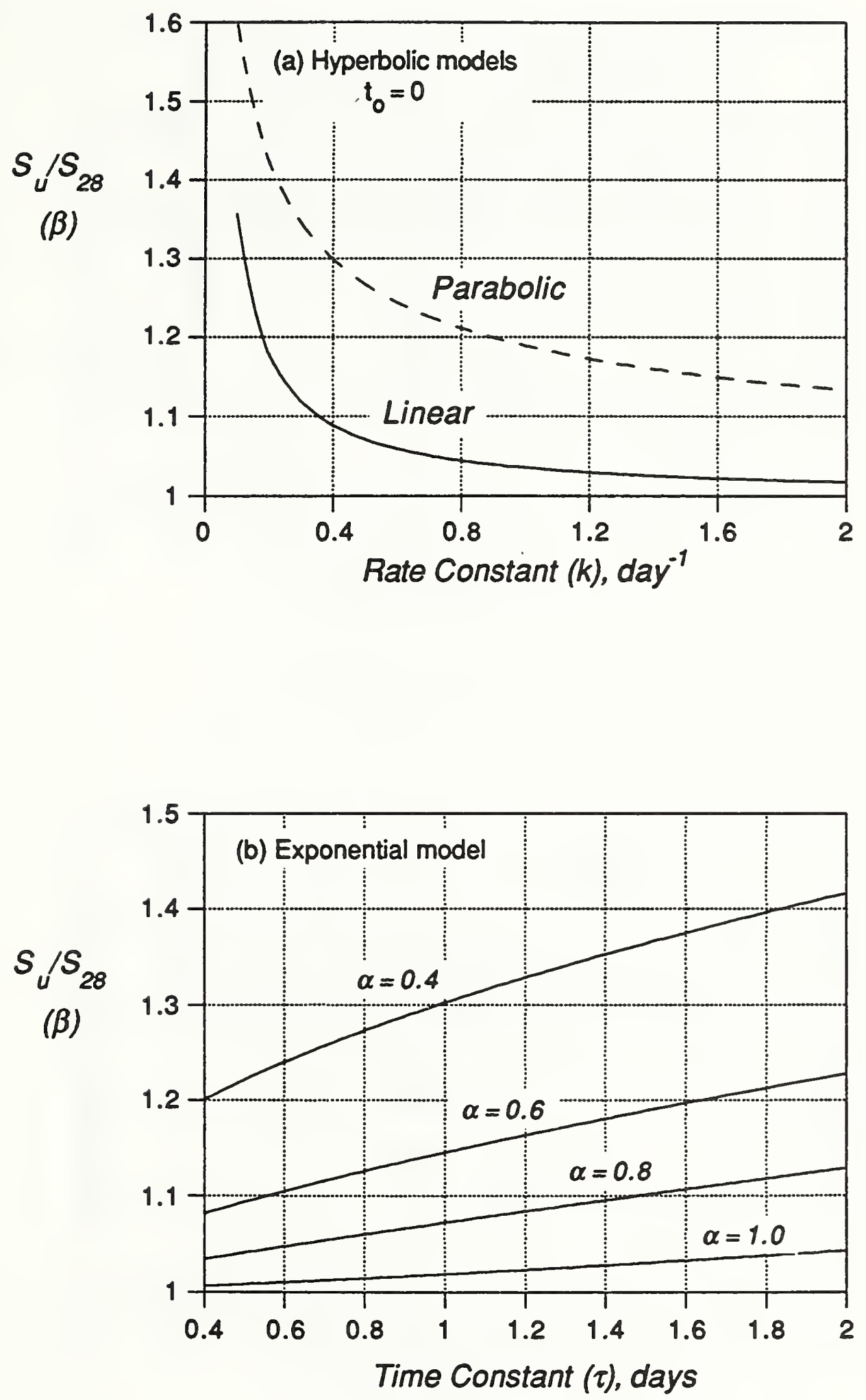

Figure 3.6 Ratio of limiting strength to 28-day strength as a function of: (a) rate constant for hyperbolic models and (b) time constant and shape factor for exponential model 

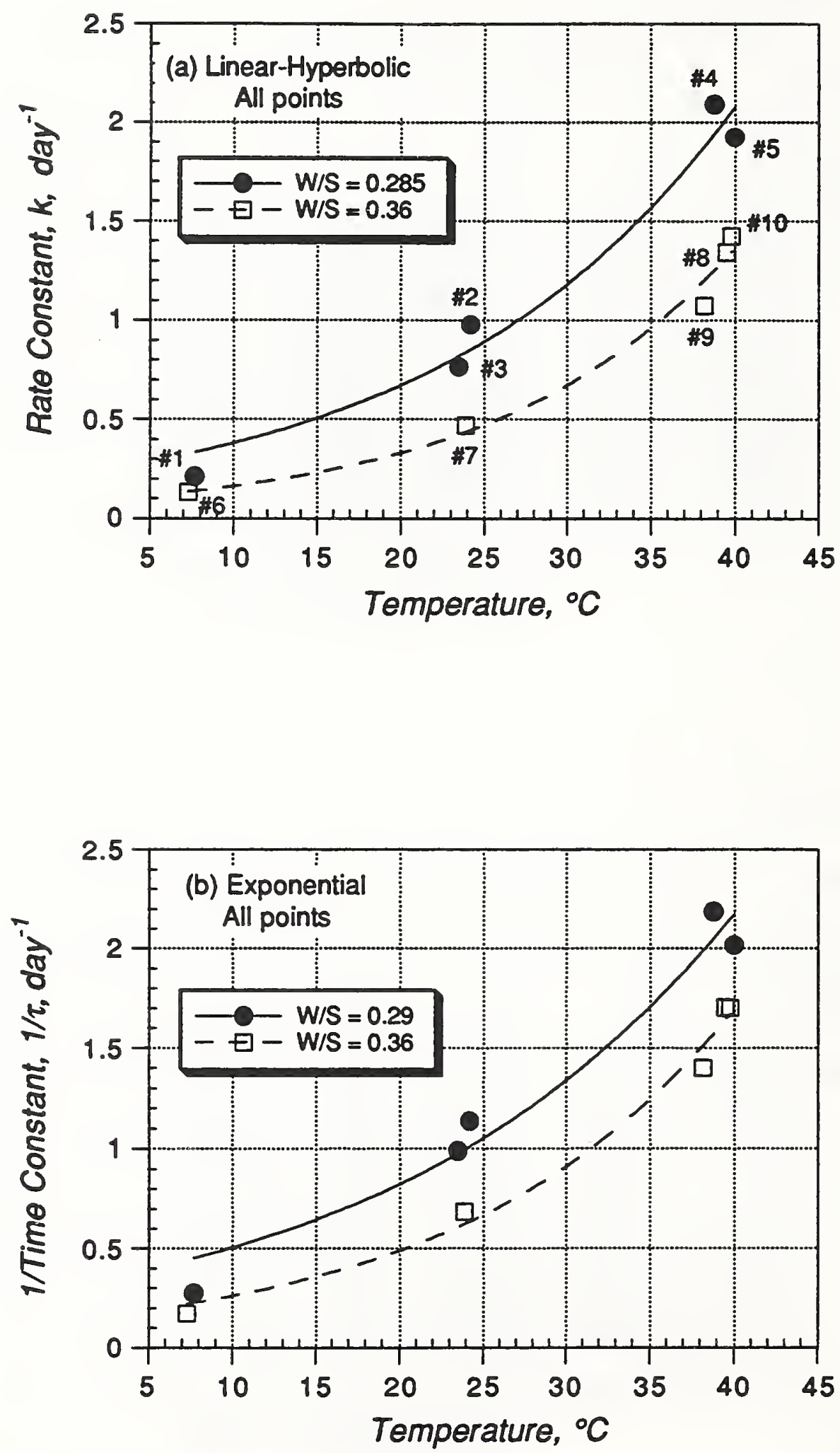

Figure 3.7 Variation of the rate constant with temperature (using Eq. (1.6)): (a) linear-hyperbolic and (b) exponential models (using all points) 

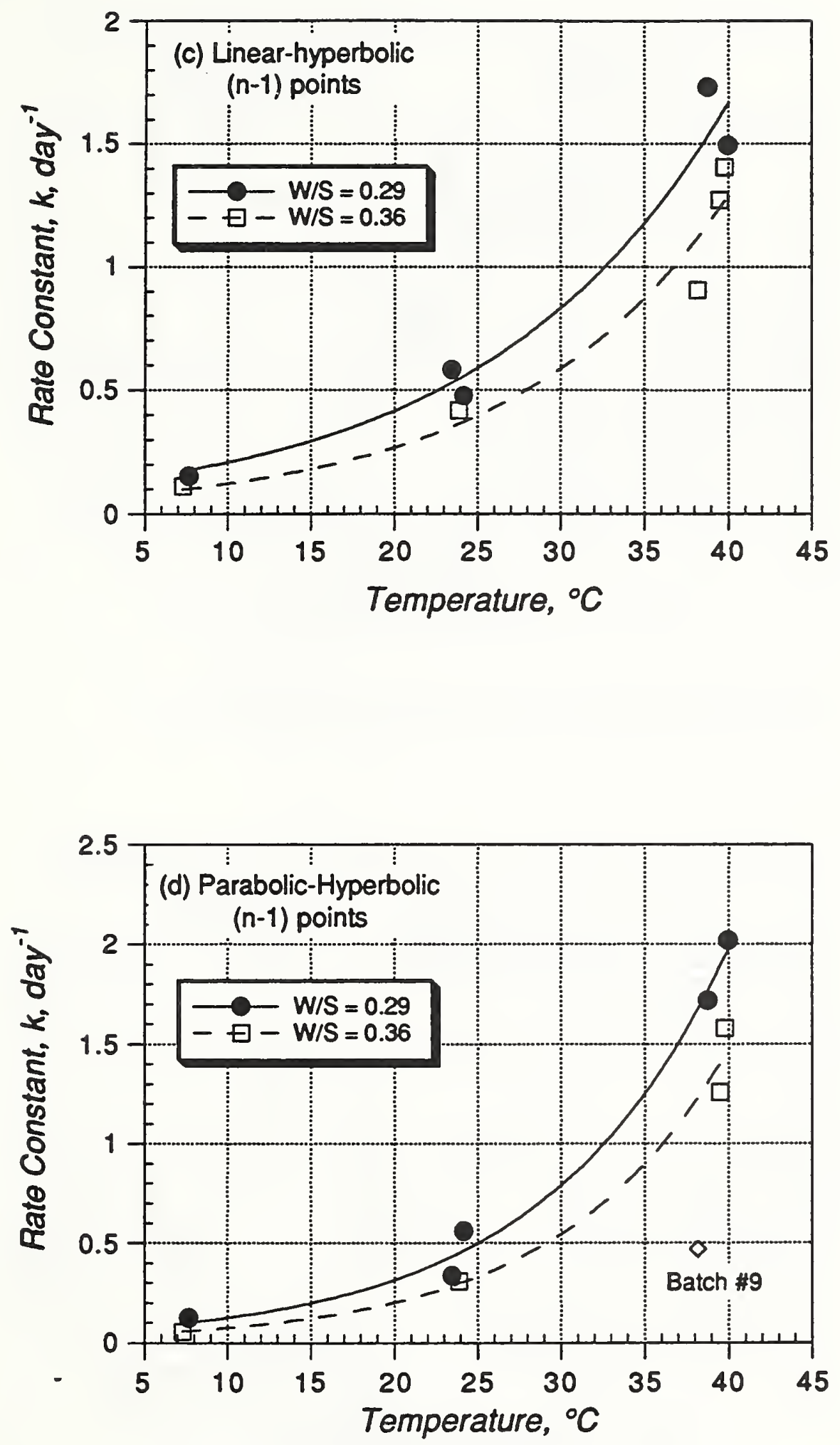

Figure 3.7 (Continued) (c) linear-hyperbolic and (d) parabolic-hyperbolic models for (n-1) points 


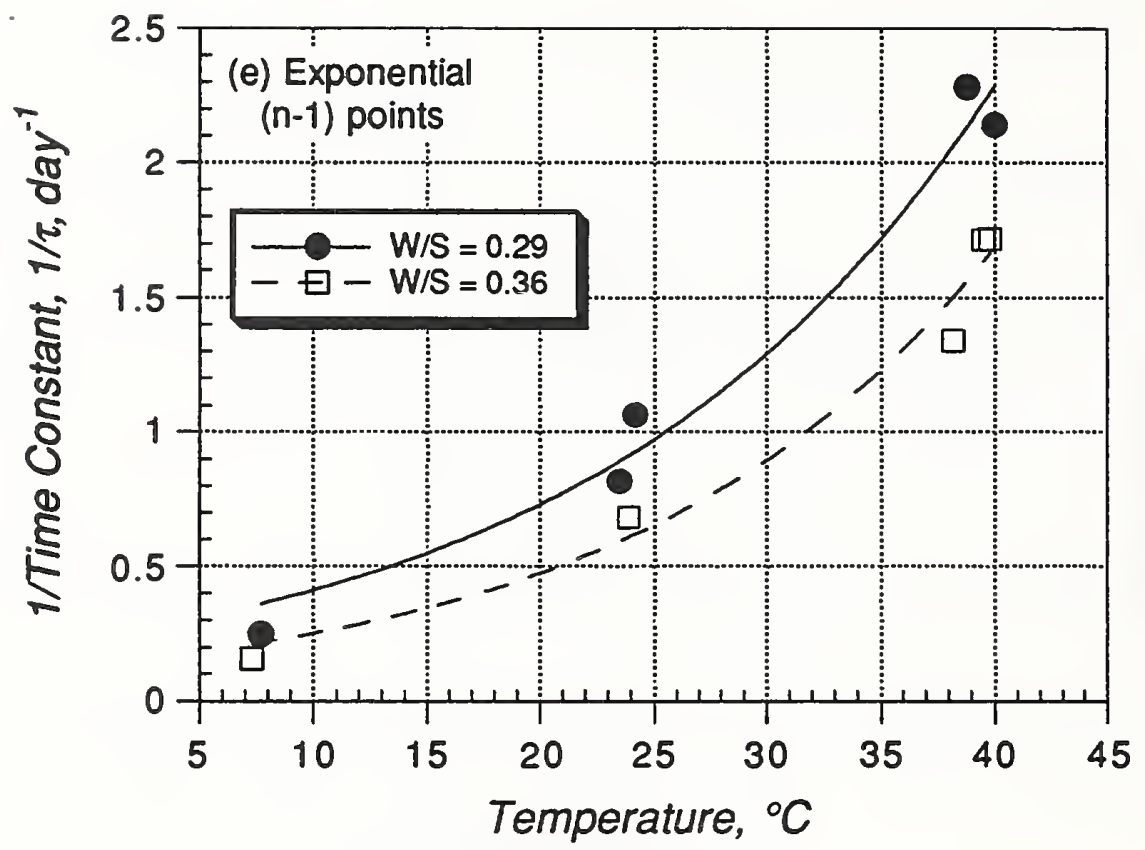

Figure 3.7 (Continued) (e) exponential model for (n-1) points

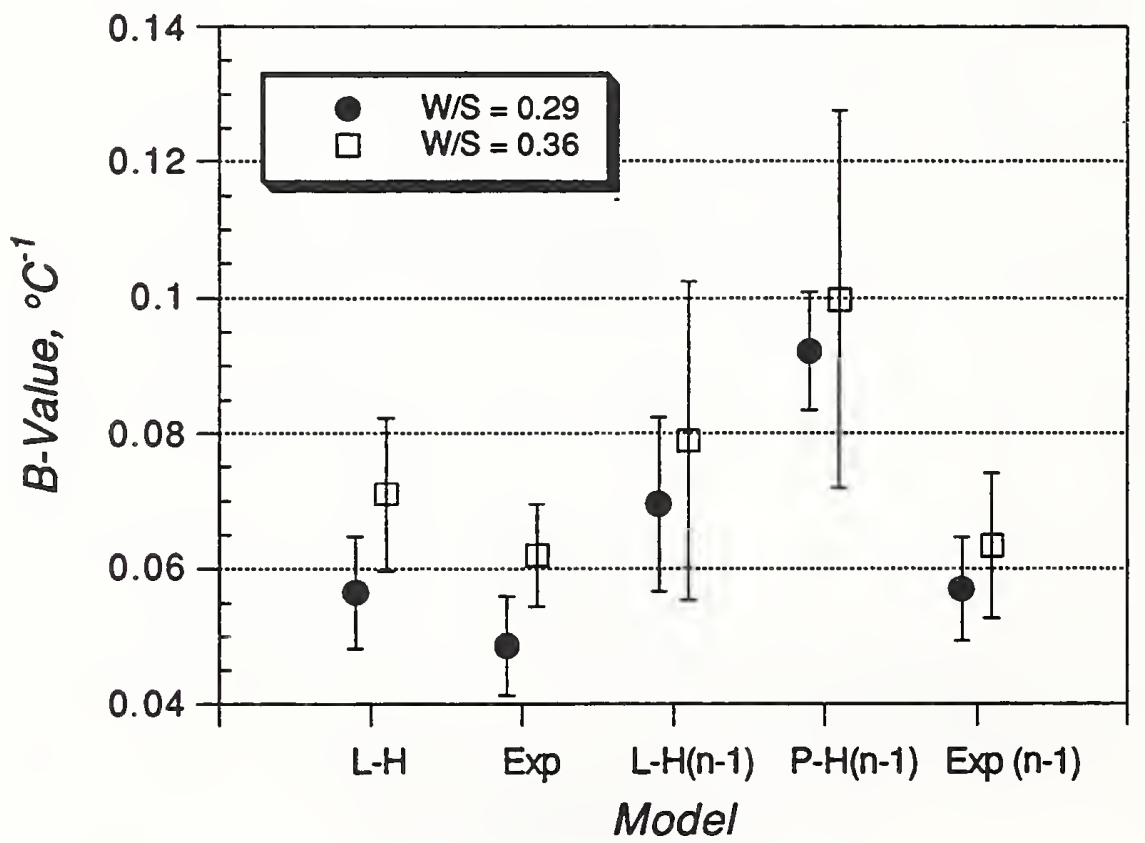

Figure 3.8 $\quad B$-values using various models to analyze strength-age data 

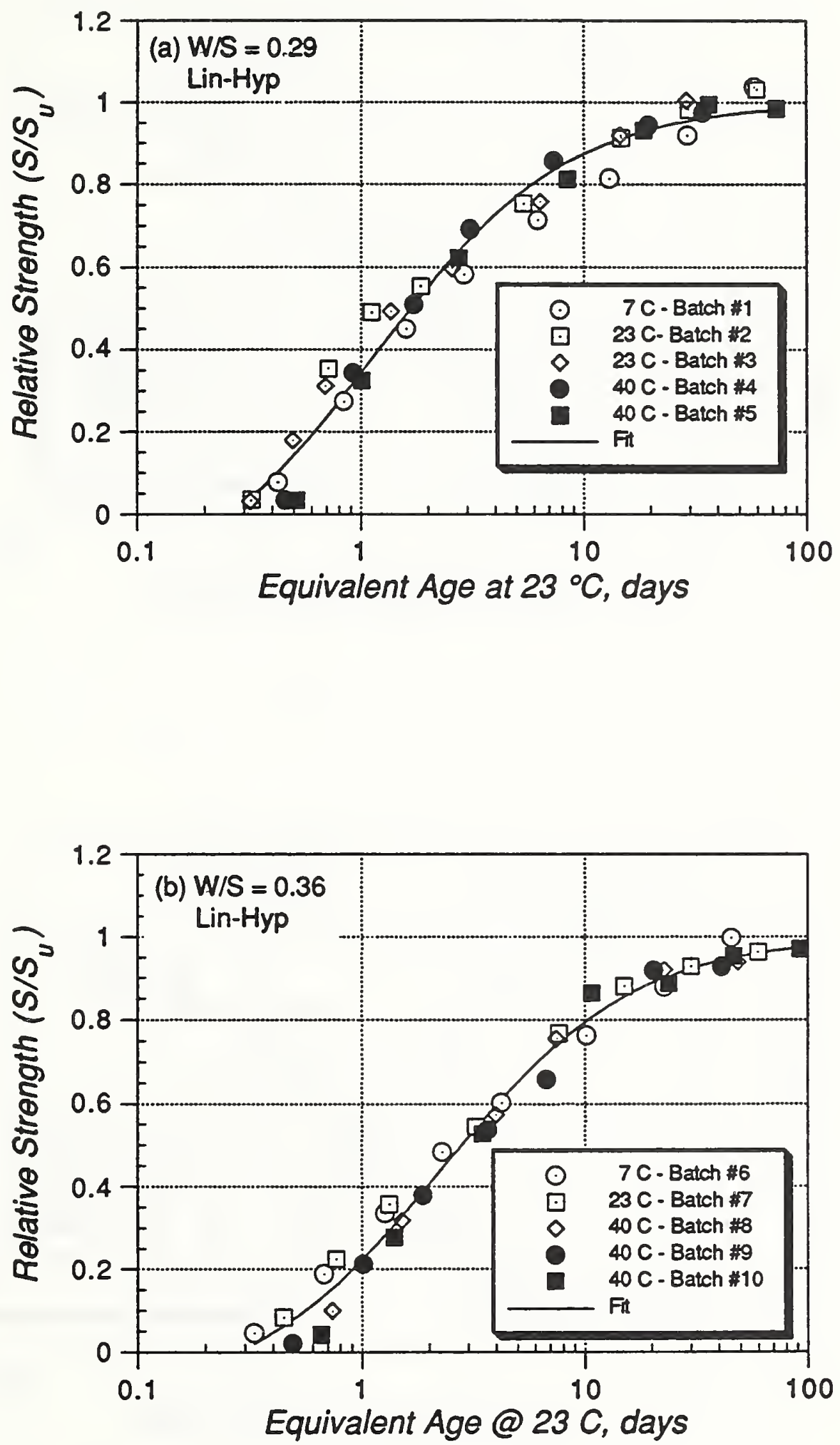

Figure 3.9 Relative strength versus equivalent age at $23^{\circ} \mathrm{C}$, linear-hyperbolic model 

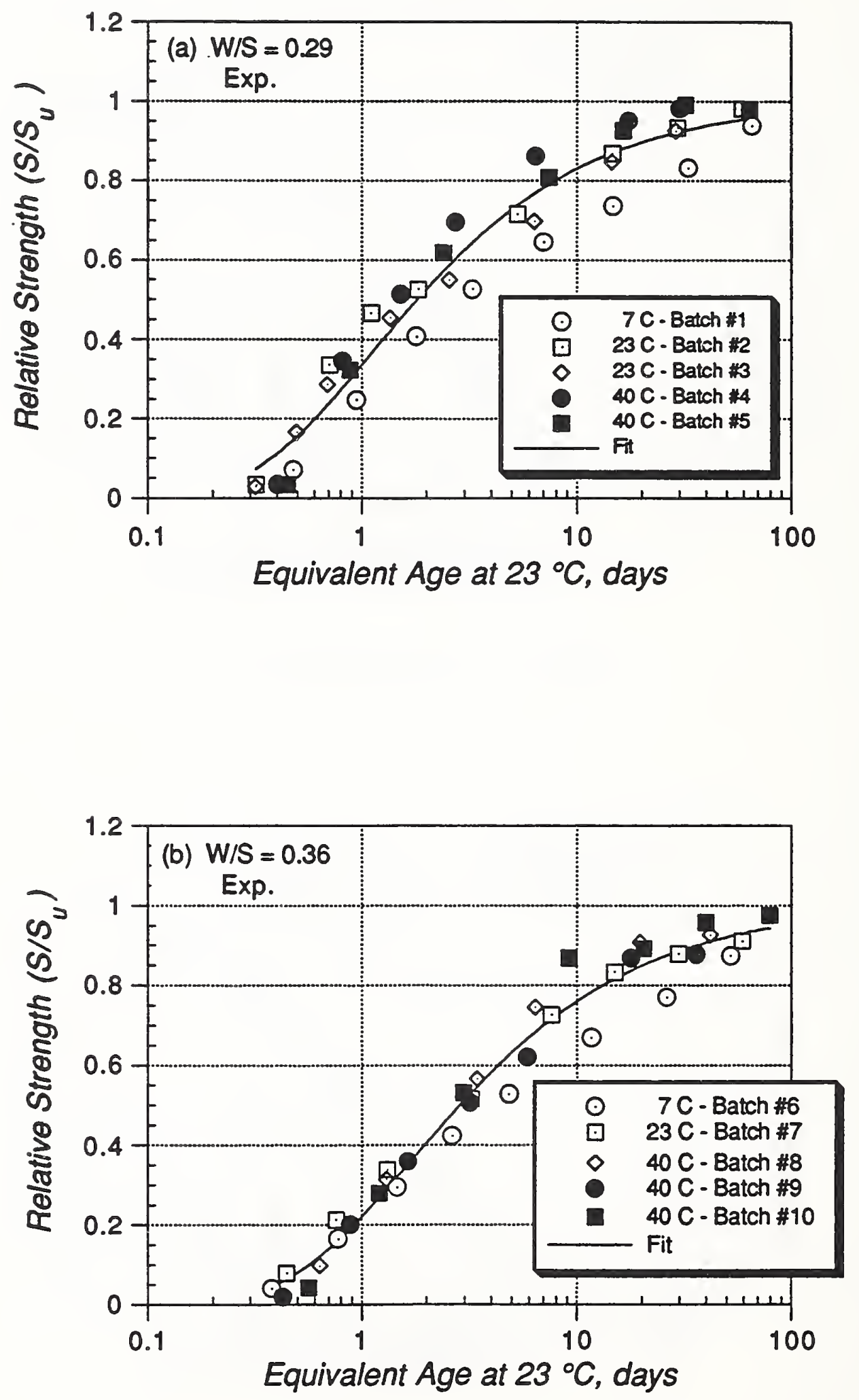

Figure 3.10 Relative strength versus equivalent age at $23^{\circ} \mathrm{C}$, exponential model 

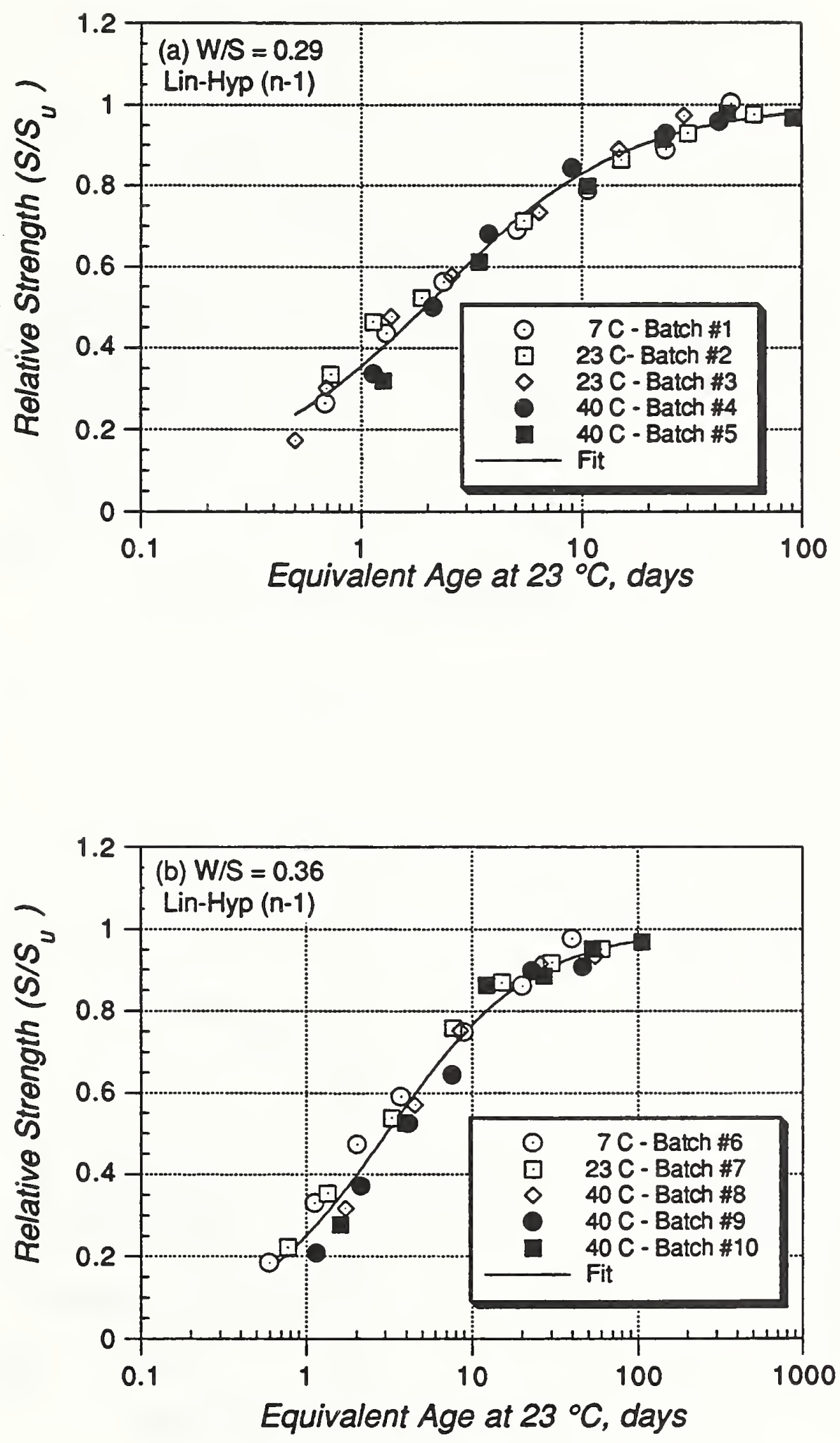

Figure 3.11 Relative strength versus equivalent age at $23^{\circ} \mathrm{C}$, linear-hyperbolic model for $(\mathrm{n}-1)$ points 

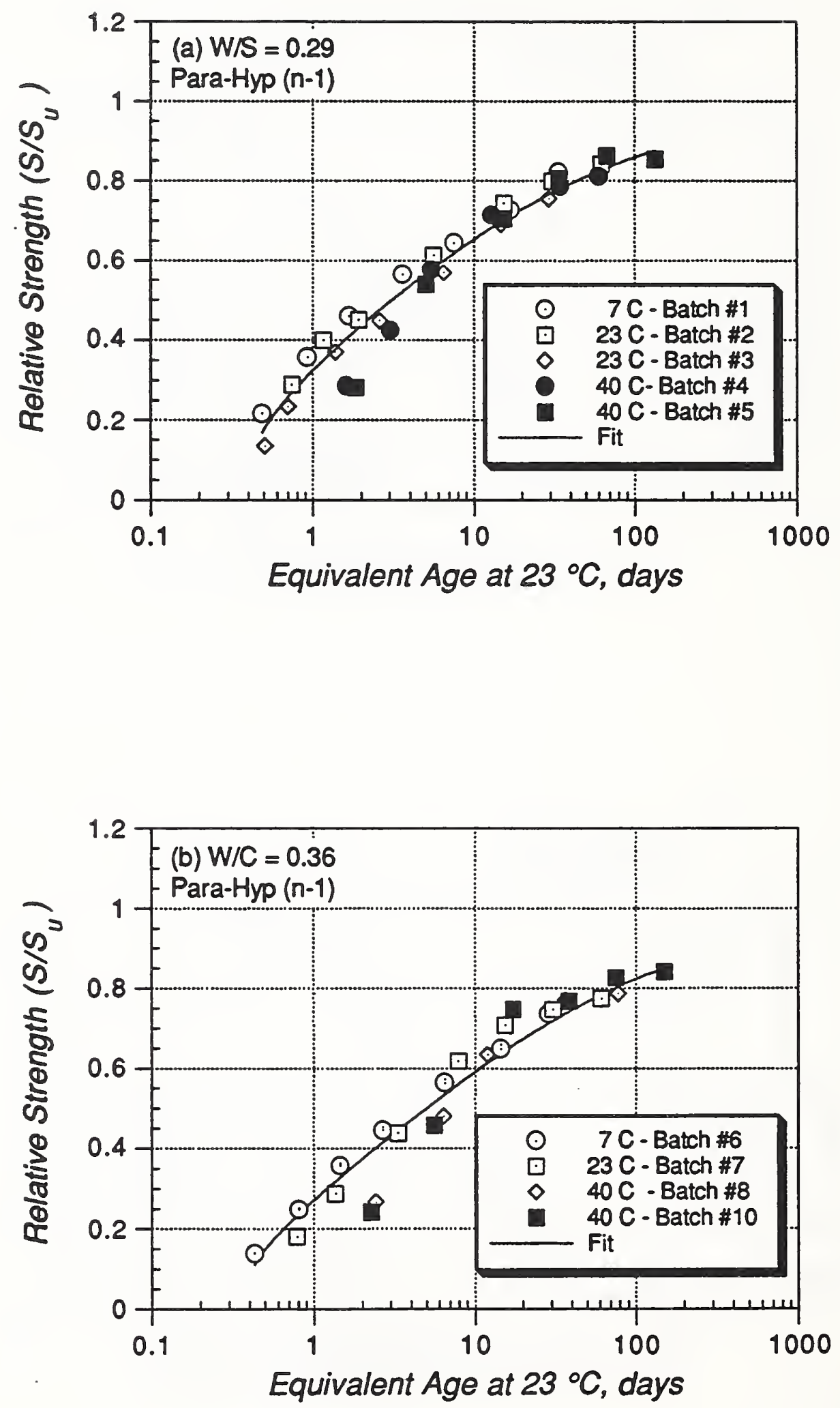

Figure 3.12 Relative strength versus equivalent age at $23^{\circ} \mathrm{C}$, parabolic-hyperbolic model for $(\mathrm{n}-1)$ points 

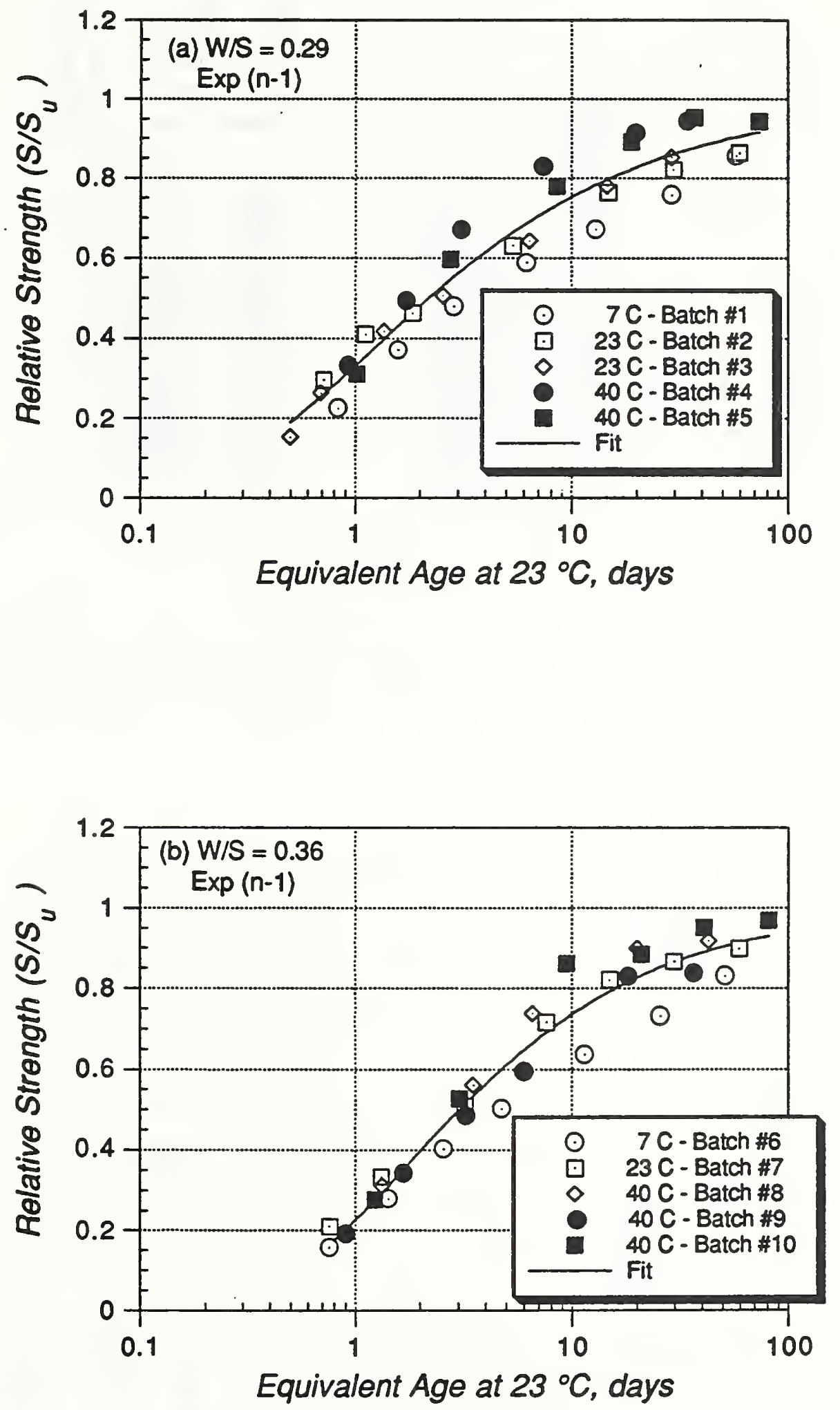

Figure 3.13 Relative strength versus equivalent age at $23^{\circ} \mathrm{C}$, exponential model for (n-1) points 


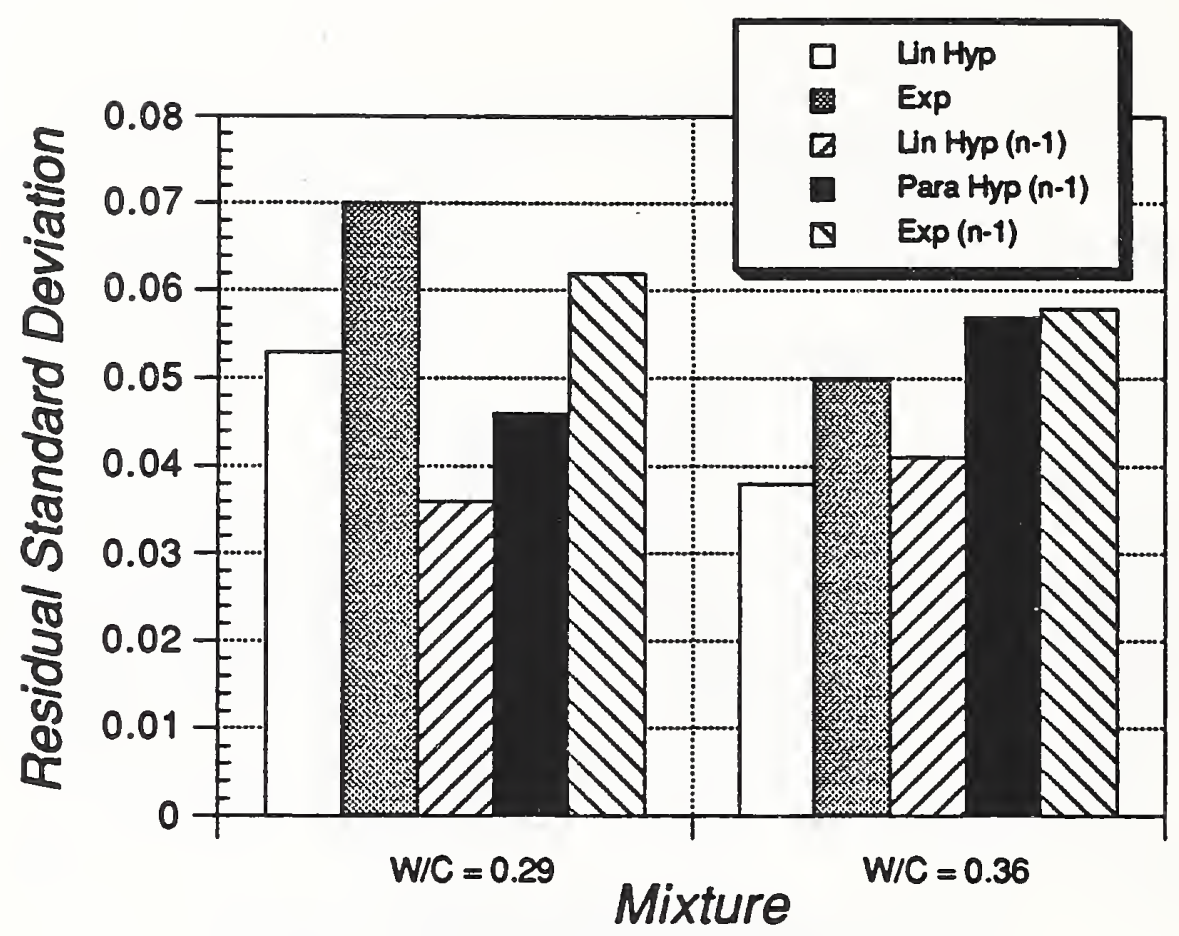

Figure 3.14 Residual standard deviation of relative strength versus equivalent age models

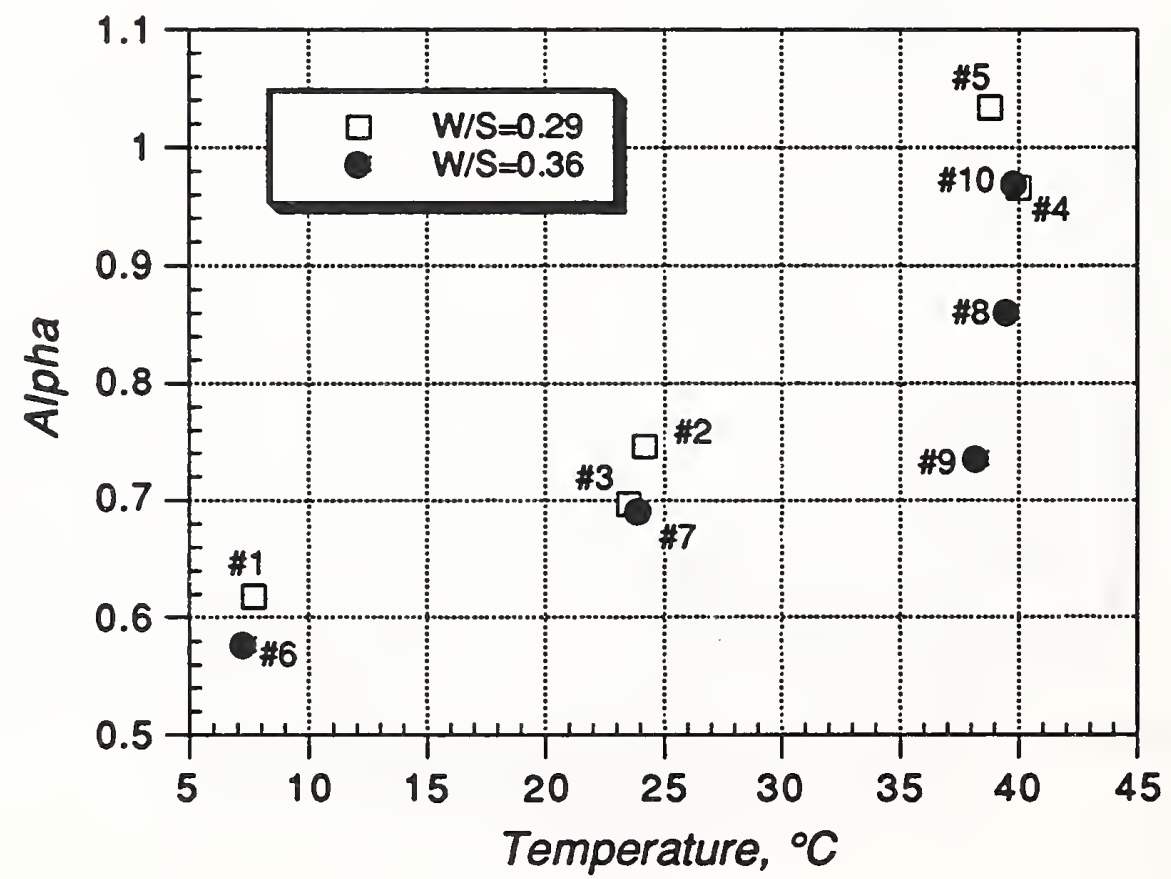

Figure 3.15 Variation of shape parameter in exponential model with curing temperature, all points considered 

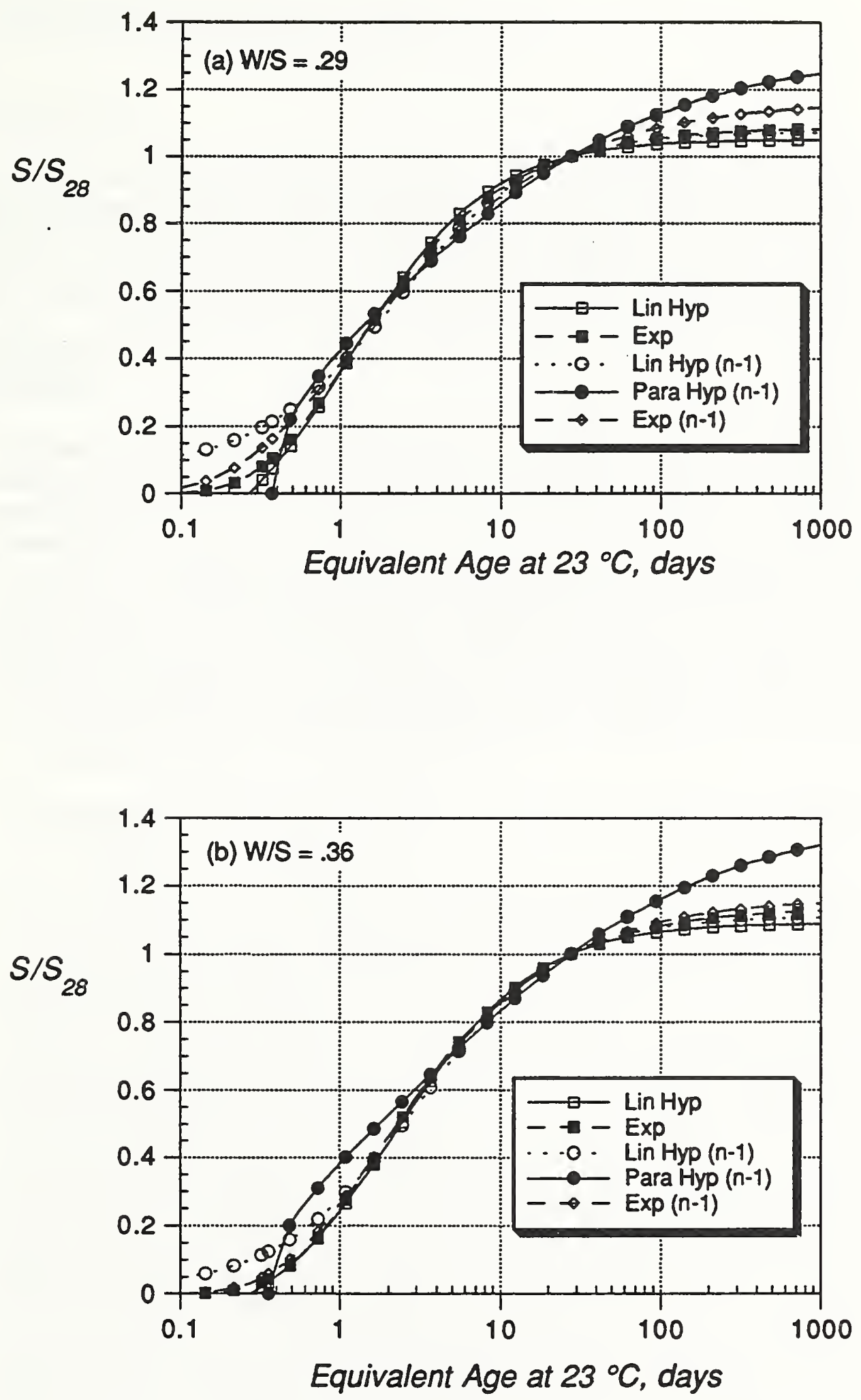

Figure 3.16 Best-fit models of fraction of 28-day strength versus equivalent age at $23^{\circ} \mathrm{C}$ 


\subsection{Conclusions}

The objective of this study was to explore the applicability of the maturity method to describe strength development of mixtures with low ratios of water-to-cementitious solids and incorporating $10 \%$ (by mass of cement) of silica fume. To achieve this objective, mortar cubes were prepared and water-cured under isothermal conditions. The resulting strength-age data were systematically analyzed to account for the combined effects of time and temperature on strength development.

The following represent the major conclusions of this study. Each conclusion is followed with a brief discussion.

(1) The maturity method is applicable for describing the effects of time and temperature on the strength development of the low water-to-cementitious solids ratio mixtures that were investigated.

The strength-age data for each curing temperature were systematically analyzed to determine the effect of curing temperature on the rate constant for strength development. This permitted the conversion of the actual test ages to equivalent ages at a constant curing temperature of $23^{\circ} \mathrm{C}$. In addition, the strength values were converted to relative strength by dividing the strength values in each batch by the corresponding "limiting" strengths obtained from regression analysis. When the relative strengths were plotted as a function of equivalent age, the data were grouped about a single best-fit curve (Fig. 3.9). Thus the applicability of the maturity method has been demonstrated.

(2) The linear-hyperbolic strength-age model is suitable for analyzing the strength development of the mixtures that were investigated.

This study afforded the opportunity to investigate three different strength-age models: the linear-hyperbolic model, the parabolic-hyperbolic model, and the exponential model. The results showed that none of the models was clearly superior in describing the strength development of the various mortar batches. For the range of data in this study, the linearhyperbolic model gave the best over-all results in representing relative strength as a function of equivalent age (Fig. 3.14). Thus the linear-hyperbolic model is suggested for analyzing strength-age data obtained form isothermal curing to determine the value of the rate constant at different temperatures. The resultant rate constants are used to establish the relationship between the rate constant and the curing temperature, which is needed to determine the correct maturity function for a specific cementitious mixture. However, the linear-hyperbolic model may not be appropriate in modeling strength gain at later ages (say more than 3 months at $23^{\circ} \mathrm{C}$ ). It was shown that the "limiting" strength obtained by fitting the linearhyperbolic model to the data was lower than would be expected based on long-term strength gain studies by other investigators. When it is necessary to model long-term development under isothermal curing, the parabolic-hyperbolic model is the better choice because it predicts more realistic values of "limiting" strength based on strengths measured at routine ages (28, 56 or 91 days). The exponential model was found to be a poor choice for implementing the maturity method, because the shape parameter was found to be dependent

on curing temperature. Additional research would be needed to develop a technique for accounting for this dependence. Finally, in implementing the maturity method, it is recommended that relative strength should be expressed in terms of the strength at an 
equivalent age of 28 days. This eliminates the problem of unrealistic "limiting" strengths that may be obtained by some of the strength-gain models.

The rate constant for strength development can be related to the curing temperature using an exponential function in which the temperature sensitivity factor, $B$, is used to describe the temperature dependence.

In agreement with previous studies (Tank and Carino 1991, Carino and Tank 1992), it has been shown that a simple exponential model can be used as an alternative to the Arrhenius equation to represent the relationship between the rate constant and the curing temperature. This leads to a simpler maturity function, because it does not use the inverse of the absolute temperature as in the Arrhenius equation. In addition, the temperature sensitivity factor, $B$, has a simpler physical interpretation than the apparent activation energy used in the Arrhenius equation. For a temperature increase of $1 / B$, the rate constant increases by a factor of 2.7 .

(4) The "limiting" strengths computed by fitting the strength-age models did not decrease in a consistent manner as the curing temperature increased.

Based on experiences with conventional mixtures, it was expected that by increasing the curing temperature the "limiting" strength computed by fitting the strength-age models would decrease. However, the results did not agree with this expectation. Thus it can be theorized that the microstructure of these mixtures with low w/s values and with silica fume are not affected by curing temperature in the same way as conventional mixtures.

\subsection{Recommendations}

This exploratory study has demonstrated the potential applicability of the maturity method to represent the effects of time and temperature on the strength gain of two mortar mixtures chosen to be representative of the cementitious systems used in high-strength concrete mixtures. However, before making a general conclusion about the applicability of the maturity method to all highperformance concrete mixtures, additional research is needed. The following are some of the key studies that should be conducted.

(1) Verification of the applicability of using mortar mixtures to develop the maturity function and relative strength versus maturity index relationship of concrete.

Testing mortar cubes offers a simplification in the pre-testing required to implement the maturity method for a "new" concrete mixture. Previous work has shown that this is possible with conventional concrete (Carino and Tank 1992). Further study is required to demonstrate whether this approach is applicable to high-performance concrete. In addition, the applicability should be investigated using mixtures which may incorporate other supplementary cementitious materials besides silica fume and other admixture combinations than used in this exploratory study. Relevant technical committees, such as Committee 231 on Concrete at Early Ages of the American Concrete Institute, should take the leadership in developing a recommended format for testing, data analysis, and data reporting. 
(2) Examination of the effect of curing temperature on the long-term strength and microstructure of high-performance concrete mixtures.

One of the unexpected findings of this study was the insensitivity of the "limiting" strength to the curing temperature. This finding should be verified by additional studies. If corroborated, this could be a characteristic of high performance concrete with significant implications.

(3) Fundamental studies to determine which characteristics of the cementitious system affect the temperature sensitivity factor.

In order to reduce the amount of pre-testing required to develop the correct maturity function for a concrete mixture, it is necessary to understand which factors affect the temperature sensitivity of the rate constant for strength development. Because there are so many different combinations of factors (e.g., cement chemistry, cement particle size distribution, and admixture chemistry) that would have to be studied, it may not be feasible for one single organization to complete such a study. However, information from different laboratories can be compared and assessed if common procedures were used for testing and data analysis and if a common format were adopted for reporting data. The testing procedure and data analysis used in this, as well as in previous NIST studies, could form the basis for such a standard method. 



\section{ACKNOWLEDGMENTS}

The completion of this study was made possible by the financial support of Headquarters, U.S. Army Corps of Engineers, and of the U.S. Department of Transportation, Office of Engineering and Highway Operations, Pavements Division. In addition, we acknowledge the assistance of the following individuals in providing technical guidance in the development and formulation of the mortar mixtures:

Mr. Randall J. Carlson of Holnan, Inc.

Mr. Lawrence R. Roberts of W.R. Grace \& Co.

Mr. Art King, Mr. Guy Detwiler and Mr. Jaime Moreno of Materials Service Corp.

The assistance of Mr. Frank L. Davis, Mr. John A. Winpigler, and Mr. Ed Prosen in carrying out the experimental work is also recognized.

Finally we thank, Dr. Andy Taylor, Mr. Ken Snyder, Ms. Marcia Simon, and Dr. Mette Gieker for their careful reviews of the manuscript and for their constructive comments. 



\section{REFERENCES}

Abelbeck Software, 1990, KaleidaGraph, Ver. 2.1, Synergy Software (publisher), Reading, PA

ACI Committee 305, 1991, "Hot Weather Concreting," ACI Materials Journal, July-August 1991, pp. $417-436$.

ASTM C 305, "Standard Practice for Mechanical Mixing of Hydraulic Cement Pastes and Mortars of Plastic Consistency," 1991 Annual Book of ASTM Standards, Vol. 04.01.

ASTM C 494, "Standard Specification for Chemical Admixtures for Concrete", 1991 Annual Book of ASTM Standards, Vol. 04.02.

ASTM C 778, "Standard Specification for Standard Sand", 1991 Annual Book of ASTM Standards, Vol. 04.01.

ASTM C 1074, "Standard Practice for Estimating Concrete Strength by the Maturity Method," 1991 Annual Book of ASTM Standards, Vol. 04.02

Brown, T.L. and LeMay, H.E., 1988, Chemistry: The Central Science, 4th Ed., Prentice Hall, Englewood Cliffs, NJ, pp. 494-498.

Byfors, J., 1980, "Plain Concrete at Early Ages," Swedish Cement and Concrete Research Institute Report 3:80, 464 pp.

Carino, N. J., 1982, "Maturity Functions for Concrete," Proceedings, RILEM International Conference on Concrete at Early Ages (Paris), Ecole Nationale des Ponts et Chausses, Paris, Vol. I, pp. 123-128.

Carino, N.J., 1984, "The Maturity Method: Theory and Application," ASTM Journal of Cement, Concrete, and Aggregates, Vol. 6, No. 2, Winter, pp. 61-73.

Carino, N.J. and Clifton, J.R., 1991, "High Performance Concrete: Research Needs to Enhance its Use," Concrete International, Vol. 13, No. 9, September, pp. 70-76.

Carino, N.J. and Tank, R.C., 1992, "Maturity Functions for Concrete Made with Various Cements and Admixtures," ACI Materials Journal, Vol. 89, No. 2, March-April, pp. 188-196.

Carette, G.G. and Malhotra, V.M., 1991, "Long-Term Strength Development of Silica Fume Concrete," Compilation of Papers from CANMET/ACI International Workshop on Silica Fume in Concrete, April 7-9, 1991, Washington, D.C., pp. 179-204.

Freiesleben Hansen, P. and Pedersen J., 1977, "Maturity Computer for Controlled Curing and Hardening of Concrete," Nordisk Betong, 1, pp. 19-34.

Freiesleben Hansen, P. and Pedersen, E. J., 1985, "Curing of Concrete Structures," CEB Information Bulletin 166, May, 42 pp. 
Geiker, M., 1983, "Studies of Portland Cement Hydration by Measurements of Chemical Shrinkage and Systematic Evaluation of Hydration Curves by Means of the Dispersion Model," PhD Dissertation, Technical University of Denmark, pp 259.

Knudsen, T., 1980, "On Particle Size Distribution in Cement Hydration," Proceedings, 7th International Congress on the Chemistry of Cement (Paris, 1980), Editions Septima, Paris, Vol. II, I-170-175.

Knudsen, T., 1984, "The Dispersion Model for Hydration of Portland Cement: I. General Concepts," Cement and Concrete Research, Vol. 14, pp 622-630.

de Larrard, F. and Bostvironnois, J.L., 1991, "On the Long-Term Strength Losses of Silica-Fume High-Strength Concretes," translation of article published in Annales de L'Institut Technique du Batiment at des Travaux Publics, No. 491, February, Serie: Beton 277, pp. 26-41.

Lew, H.S. and Reichard, T.W., 1978, "Prediction of Strength of Concrete from Maturity," in Accelerated Strength Testing, SP-56, American Concrete Institute, Detroit, MI, pp. 229-248.

Malhotra, V.M. and Carino, N.J., Eds., 1991, Handbook on Nondestructive Testing of Concrete, CRC Press, Boca Raton, FL, 343 pp.

McIntosh, J. D., 1949, "Electrical Curing of Concrete," Magazine of Concrete Research, Vol. 1, No. 1 , January 1949, pp. 21-28.

Nurse, R. W., 1949, "Steam Curing of Concrete," Magazine of Concrete Research, Vol. 1, No. 2, 1949, pp. 79-88.

Read, P., Carette, G.G. and Malhotra, V.M., 1991, "Strength Development Characteristics of HighStrength Concrete Incorporating Supplementary Cementing Materials," Compilation of Papers from CANMET/ACI International Workshop on Silica Fume in Concrete, April 7-9, 1991, Washington, D.C., pp. 85-110.

Roy, D. M., and Idorn, G. M., 1982, "Hydration, Structure, and Properties of Blast Furnace Slag Cements, Mortars and Concrete," Journal of the American Concrete Institute, Vol. 79, No. 6, November-December, pp. 444-457.

Saul, A. G. A., 1951, "Principles Underlying the Steam Curing of Concrete at Atmospheric Pressure," Magazine of Concrete Research, Vol. 2, No. 6, March, pp. 127-140.

Tank, R.C. and Carino, N.J., 1991, "Rate Constant Functions for Strength Development of Concrete," ACI Materials Journal, Vol. 88, No. 1, Jan-Feb, pp. 74-83. 


\section{APPENDIX}

\section{A.1 Glossary}

The following are definitions of terms used in this report. Where applicable, the symbol used for the term is given in parentheses.

activation energy $(E)$ - the parameter in the Arrhenius equation (Eq. (1.3)) which describes the sensitivity of the rate constant to the curing temperature.

age conversion factor $(\gamma(T))$ - the factor which converts an interval of curing time at any temperature to the equivalent time interval at a reference temperature. The age conversion factor is the ratio of the rate constants at the two curing temperatures (see Eqs. (1.4), (1.5) and (1.8)).

datum temperature $\left(T_{0}\right)$ - the temperature that is subtracted from the measured concrete temperature for calculating the temperature-time factor according to Eq. (1.1).

equivalent age $\left(t_{e}\right)$ - the number of days or hours at a specified reference temperature required to produce a maturity equal to the maturity achieved by a curing period at temperatures different from the specified temperature (Eq.(1.4).

limiting strength $\left(S_{u}\right)$ - a parameter in the strength-age function which represents that strength that is approached as age approaches infinity.

maturity -- the extent of evolution of the properties of a cementitious mixture. This term is usually used to describe the extent of relative strength development of concrete. However, the term can also be applied to the evolution of other properties which are dependent on the chemical reactions which occur in the cementitious materials. At any age, maturity is dependent on the curing history.

maturity function -- a mathematical expression that uses the measured temperature history of a cementitious mixture during the curing period to calculate an index that is indicative of the maturity at the end of that period.

maturity index -- an indicator of maturity that is calculated from the temperature history of the cementitious mixture by using a maturity function. The computed index is indicative of maturity provided there has been a sufficient supply of water for hydration or pozzolanic reaction of the cementitious materials during the time used in the calculation. Two widely used maturity indexes are the temperature-time factor and the equivalent age.

maturity method - a technique for estimating concrete strength that is based on the assumption that samples of a given concrete mixture attain equal strengths if they attain equal values of the maturity index.

rate constant $(k)$ - one of the parameters in the equation of strength versus age under isothermal curing. The inverse of the rate constant equals the age to attain a certain fraction of the limiting strength.

strength-age function - an equation describing the development of strength of a cementitious mixture as a function of age at a constant curing temperature. 
strength-maturity relationship - an empirical relationship between compressive strength and maturity index that is obtained by testing specimens whose temperature history up to the time of test has been recorded.

temperature-time factor - the maturity index computed using the Nurse-Saul function, Eq. (1.1)

temperature sensitivity factor $(B)$ - the parameter in the exponential equation given by Eq. (1.6) which describes the sensitivity of the rate constant to the curing temperature.

$t_{0}$ - the age when strength development is assumed to begin according to the linear hyperbolic or parabolic hyperbolic strength-age functions. 


\section{A.2 Strength-Age Data}

Table A.1 Average compressive strengths and masses of mortar cubes cured at $7^{\circ} \mathrm{C}$

\begin{tabular}{|c|c|c|c|c|c|}
\hline $\mathrm{W} / \mathrm{S}=0.29$ & Batch\# 1 & & & & \\
\hline $\mathrm{T}_{\text {cum }}{ }^{\circ}$ & $\begin{array}{l}\text { Age } \\
\text { (days) }\end{array}$ & $\begin{array}{l}\text { Avg. Strength } \\
(\mathrm{MPa})\end{array}$ & $\begin{array}{c}\text { Strength CV } \\
(\%)\end{array}$ & $\begin{array}{l}\text { Avg. Mass } \\
\text { (gm) }\end{array}$ & $\begin{array}{c}\text { Mass CV } \\
(\%)\end{array}$ \\
\hline 7.7 & 1.010 & 8.23 & 3.5 & 303.5 & 0.5 \\
\hline 7.8 & 1.993 & 29.17 & 4.9 & 303.9 & 0.7 \\
\hline 7.5 & 3.791 & 48.00 & 2.6 & 303.2 & 0.7 \\
\hline 7.3 & 6.896 & 61.92 & 2.4 & 303.5 & 0.4 \\
\hline \multirow[t]{4}{*}{7.2} & 14.842 & 75.99 & 2.3 & 306.5 & 0.3 \\
\hline & 30.986 & 86.76 & 1.4 & 307.2 & 0.4 \\
\hline & 69.756 & 97.90 & 2.8 & 308.1 & 0.1 \\
\hline & 138.749 & $110.50^{*}$ & 2.5 & 307.2 & 0.5 \\
\hline $\mathrm{W} / \mathrm{S}=0.36$ & \multicolumn{5}{|l|}{ Batch \#6 } \\
\hline $\begin{array}{c}\mathrm{T}_{\text {cum }} \\
\left({ }^{\circ} \mathrm{C}\right)\end{array}$ & $\begin{array}{l}\text { Age } \\
\text { (days) }\end{array}$ & $\begin{array}{l}\text { Avg. Strength } \\
(\mathrm{MPa})\end{array}$ & $\begin{array}{c}\text { Strength CV } \\
(\%)\end{array}$ & $\begin{array}{l}\text { Avg. Mass } \\
\text { (gm) }\end{array}$ & $\begin{array}{c}\text { Mass CV } \\
(\%)\end{array}$ \\
\hline 7.3 & 1.008 & 3.89 & 2.8 & 294.3 & 0.3 \\
\hline 7.3 & 2.060 & 15.93 & 2.2 & 296.3 & 0.3 \\
\hline 7.3 & 3.877 & 28.42 & 0.5 & 295.7 & 0.8 \\
\hline 6.9 & 6.988 & 40.82 & 3.5 & 298.7 & 0.2 \\
\hline \multirow[t]{4}{*}{6.8} & 12.886 & 50.96 & 3.9 & 296.9 & 0.8 \\
\hline & 31.049 & 64.54 & 1.2 & 298.2 & 0.3 \\
\hline & 69.856 & 74.24 & 0.6 & 297.1 & 0.7 \\
\hline & 138.852 & 84.23 & 2.3 & 299.3 & 0.8 \\
\hline
\end{tabular}

${ }^{*} \mathrm{~T}_{\text {cum }}=$ cumulative weighted average temperature $\mathrm{n}=4$ 
Table A.2 Average compressive strengths and masses of mortar cubes cured at $23^{\circ} \mathrm{C}$

\begin{tabular}{|c|c|c|c|c|c|}
\hline$W / S=0.29$ & Batch \#2 & & & & \\
\hline $\begin{array}{c}\mathrm{T}_{\text {cum }} \\
\left({ }^{\circ} \mathrm{C}\right)\end{array}$ & $\begin{array}{c}\text { Age } \\
\text { (days) }\end{array}$ & $\begin{array}{c}\text { Avg. Strength } \\
(\mathrm{MPa})\end{array}$ & $\begin{array}{c}\text { Strength CV } \\
(\%)\end{array}$ & $\begin{array}{l}\text { Avg. Mass } \\
\text { (gm) }\end{array}$ & $\begin{array}{c}\text { Mass CV } \\
(\%)\end{array}$ \\
\hline 24.2 & 0.303 & 4.05 & 7.2 & 302.5 & 0.3 \\
\hline 24.7 & 0.668 & 40.77 & 4.8 & 305.8 & 0.2 \\
\hline 24.4 & 1.044 & 56.50 & 2.7 & 304.8 & 1.0 \\
\hline \multirow[t]{5}{*}{24.7} & 1.733 & 63.73 & 4.9 & 305.4 & 0.4 \\
\hline & 5.027 & 86.73 & 1.9 & 305.3 & 0.8 \\
\hline & 13.797 & 105.13 & 3.9 & 307.8 & 0.4 \\
\hline & 27.801 & 113.05 & 2.6 & 304.8 & 0.8 \\
\hline & 55.792 & 118.80 & 5.5 & 307.8 & 1.0 \\
\hline $\mathrm{W} / \mathrm{S}=0.29$ & \multicolumn{5}{|l|}{ Batch \#3 } \\
\hline $\begin{array}{c}\mathrm{T}_{\text {cum }} \\
\left({ }^{\circ} \mathrm{C}\right)\end{array}$ & $\begin{array}{l}\text { Age } \\
\text { (days) }\end{array}$ & $\begin{array}{c}\text { Avg. Strength } \\
(\mathrm{MPa})\end{array}$ & $\begin{array}{c}\text { Strength CV } \\
(\%)\end{array}$ & $\begin{array}{l}\text { Avg. Mass } \\
\text { (gm) }\end{array}$ & $\begin{array}{c}\text { Mass CV } \\
(\%)\end{array}$ \\
\hline 23.5 & 0.312 & 3.72 & 4.5 & 304.2 & 0.4 \\
\hline 23.8 & 0.485 & 21.33 & 4.6 & 305.1 & 1.0 \\
\hline 23.9 & 0.675 & 36.98 & 2.7 & 306.5 & 0.2 \\
\hline 24.1 & 1.328 & 58.51 & 2.6 & 306.6 & 0.2 \\
\hline 23.9 & 2.494 & 70.79 & 4.6 & 306.3 & 0.8 \\
\hline 23.9 & 6.224 & 89.91 & 0.9 & 308.1 & 0.4 \\
\hline 23.7 & 14.201 & 109.09 & 0.9 & 307.0 & 0.5 \\
\hline 23.9 & 28.228 & 119.25 & 0.5 & 307.8 & 1.1 \\
\hline $\mathrm{W} / \mathrm{S}=0.36$ & \multicolumn{5}{|l|}{ Batch \#7 } \\
\hline $\begin{array}{c}\mathrm{T}_{\text {cum }} \\
\left({ }^{\circ} \mathrm{C}\right)\end{array}$ & $\begin{array}{l}\text { Age } \\
\text { (days) }\end{array}$ & $\begin{array}{c}\text { Avg. Strength } \\
(\mathrm{MPa})\end{array}$ & $\begin{array}{c}\text { Strength CV } \\
(\%)\end{array}$ & $\begin{array}{l}\text { Avg. Mass } \\
\text { (gm) }\end{array}$ & $\begin{array}{c}\text { Mass CV } \\
(\%)\end{array}$ \\
\hline 23.9 & 0.422 & 7.73 & 2.2 & 293.5 & 1.1 \\
\hline 24.1 & 0.719 & 20.81 & 2.6 & 293.8 & 0.5 \\
\hline 24.4 & 1.247 & 33.04 & 0.3 & 293.8 & 0.2 \\
\hline 24.5 & 3.052 & 50.30 & 2.3 & 294.2 & 0.4 \\
\hline 24.1 & 7.210 & 70.82 & 1.9 & 294.4 & 1.1 \\
\hline 23.9 & 14.139 & 81.16 & 0.9 & 295.9 & 0.3 \\
\hline 23.9 & 28.170 & $85.65^{*}$ & 6.2 & 296.7 & 0.7 \\
\hline 23.8 & 56.106 & 88.82 & 6.6 & 296.0 & 0.3 \\
\hline
\end{tabular}


Table A.3 Average compressive strengths and masses of mortar cubes cured at $40^{\circ} \mathrm{C}$, W/S $=0.29$

\begin{tabular}{|c|c|c|c|c|c|}
\hline$W / S=0.29$ & Batch \#4 & & & & \\
\hline $\mathrm{T}_{\text {cum }}$ & $\begin{array}{c}\text { Age } \\
\text { (days) }\end{array}$ & $\begin{array}{l}\text { Avg. Strength } \\
\text { (MPa) }\end{array}$ & $\begin{array}{c}\text { Strength CV } \\
(\%)\end{array}$ & $\begin{array}{l}\text { Avg. Mass } \\
\text { (gm) }\end{array}$ & $\begin{array}{c}\text { Mass CV } \\
(\%)\end{array}$ \\
\hline 38.8 & 0.188 & 4.10 & 12.0 & 298.7 & 0.8 \\
\hline 39.4 & 0.381 & 41.51 & 3.1 & 305.3 & 0.3 \\
\hline 39.4 & 0.706 & 61.69 & 2.8 & 303.1 & 0.7 \\
\hline 39.6 & 1.279 & 83.63 & 0.4 & 305.6 & 0.3 \\
\hline 39.5 & 3.065 & 103.64 & 2.8 & 304.8 & 0.8 \\
\hline 39.5 & 8.060 & 114.14 & 4.8 & 304.8 & 0.6 \\
\hline 39.6 & 14.047 & 117.88 & 1.7 & 303.2 & 1.2 \\
\hline $\mathrm{W} / \mathrm{S}=0.29$ & Batch \#5 & & & & \\
\hline $\mathrm{T}_{\text {cum }}$ & $\begin{array}{c}\text { Age } \\
\text { (days) }\end{array}$ & $\begin{array}{l}\text { Avg. Strength } \\
(\mathrm{MPa})\end{array}$ & $\begin{array}{c}\text { Strength CV } \\
(\%)\end{array}$ & $\begin{array}{l}\text { Avg. Mass } \\
\text { (gm) }\end{array}$ & $\begin{array}{c}\text { Mass CV } \\
(\%)\end{array}$ \\
\hline 40.0 & 0.197 & 4.07 & 1.3 & 303.5 & 0.3 \\
\hline 40.5 & 0.387 & 38.76 & 3.9 & 305.6 & 0.3 \\
\hline 40.0 & 1.053 & 74.12 & 0.4 & 307.5 & 0.4 \\
\hline 40.3 & 3.244 & 96.80 & 2.8 & 305.9 & 0.6 \\
\hline 40.2 & 7.158 & $110.83^{* *}$ & 4.8 & 307.1 & 0.4 \\
\hline \multirow[t]{2}{*}{40.2} & 14.060 & 118.45 & 2.8 & 307.7 & 0.6 \\
\hline & 28.074 & $117.17^{*}$ & 5.3 & 307.9 & 0.5 \\
\hline
\end{tabular}

${ }_{n=4,}^{*}{ }_{n=5}$ 
Table A.3 (Cont'd.) Average compressive strengths and masses of mortar cubes cured at $40^{\circ} \mathrm{C}$, $\mathrm{W} / \mathrm{S}=0.36$

\begin{tabular}{|c|c|c|c|c|c|}
\hline $\mathrm{W} / \mathrm{S}=0.36$ & Batch \#8 & & & & \\
\hline $\mathrm{T}_{\text {cum }}$ & $\begin{array}{l}\text { Age } \\
\text { (days) }\end{array}$ & $\begin{array}{c}\text { Avg. Strength } \\
(\mathrm{MPa})\end{array}$ & $\begin{array}{c}\text { Strength CV } \\
(\%)\end{array}$ & $\begin{array}{l}\text { Avg. Mass } \\
\text { (gm) }\end{array}$ & $\begin{array}{c}\text { Mass CV } \\
(\%)\end{array}$ \\
\hline 39.5 & 0.229 & 8.93 & 2.9 & 290.6 & 0.7 \\
\hline 39.6 & 0.469 & 28.65 & 0.3 & 294.2 & 0.1 \\
\hline 39.8 & 1.235 & 51.68 & 3.0 & 295.1 & 0.7 \\
\hline \multirow[t]{3}{*}{39.4} & 2.317 & 68.10 & 0.9 & 295.6 & 0.2 \\
\hline & 7.071 & 82.85 & 1.3 & 294.8 & 0.2 \\
\hline & 15.077 & 84.57 & 3.8 & 296.2 & 0.6 \\
\hline $\mathrm{W} / \mathrm{S}=0.36$ & \multicolumn{5}{|l|}{ Batch \#9 } \\
\hline $\begin{array}{c}\mathrm{T}_{\text {cum }} \\
\left({ }^{\circ} \mathrm{C}\right)\end{array}$ & $\begin{array}{c}\text { Age } \\
\text { (days) }\end{array}$ & $\begin{array}{c}\text { Avg. Strength } \\
(\mathrm{MPa})\end{array}$ & $\begin{array}{c}\text { Strength CV } \\
(\%)\end{array}$ & $\begin{array}{l}\text { Avg. Mass } \\
\text { (gm) }\end{array}$ & $\begin{array}{c}\text { Mass CV } \\
(\%)\end{array}$ \\
\hline 38.2 & 0.167 & 1.83 & 1.4 & 291.8 & 0.5 \\
\hline 39.2 & 0.346 & 19.29 & 0.9 & 295.1 & 0.3 \\
\hline 39.4 & 0.642 & 84.12 & 1.4 & 292.4 & 0.2 \\
\hline 39.5 & 1.246 & 48.72 & 6.8 & 291.8 & 0.3 \\
\hline \multirow[t]{3}{*}{39.4} & 2.303 & 59.81 & 10.3 & 296.2 & 0.2 \\
\hline & 6.962 & 83.34 & 1.5 & 294.7 & 0.1 \\
\hline & 13.988 & 84.26 & 2.8 & 295.0 & 0.3 \\
\hline$W / S=0.36$ & \multicolumn{5}{|l|}{ Batch \#10 } \\
\hline $\begin{array}{c}\mathrm{T}_{\text {cum }} \\
\left({ }^{\circ} \mathrm{C}\right)\end{array}$ & $\begin{array}{c}\text { Age } \\
\text { (days) }\end{array}$ & $\begin{array}{c}\text { Avg. Strength } \\
(\mathrm{MPa})\end{array}$ & $\begin{array}{c}\text { Strength CV } \\
(\%)\end{array}$ & $\begin{array}{l}\text { Avg. Mass } \\
(\mathrm{gm})\end{array}$ & $\begin{array}{c}\text { Mass CV } \\
(\%)\end{array}$ \\
\hline 39.8 & 0.199 & 3.70 & 1.4 & 296.0 & 0.6 \\
\hline 40.1 & 0.425 & 24.56 & 1.8 & 297.7 & 0.2 \\
\hline 40.1 & 1.051 & 46.59 & 3.7 & 297.4 & 0.3 \\
\hline 40.1 & 3.256 & 76.25 & 3.0 & 299.0 & 0.3 \\
\hline $40 . I$ & 7.235 & 3.70 & 3.8 & 297.6 & 0.6 \\
\hline 40.1 & 14.119 & 84.12 & 1.3 & 297.3 & 0.6 \\
\hline 40.0 & 28.115 & 85.64 & 1.1 & 298.2 & 0.4 \\
\hline
\end{tabular}


A.3 Early-Age Temperature Histories

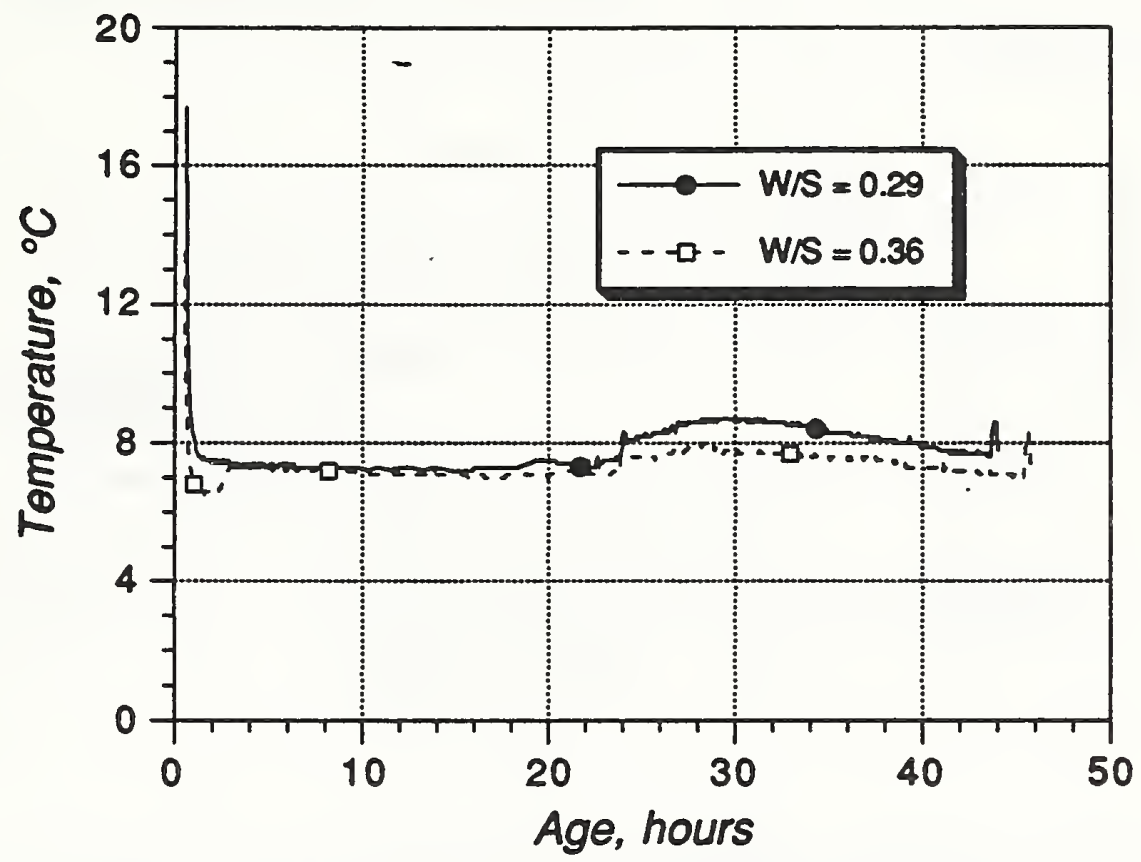

Figure A.1 Early-age temperature histories for cubes cured at $7^{\circ} \mathrm{C}$

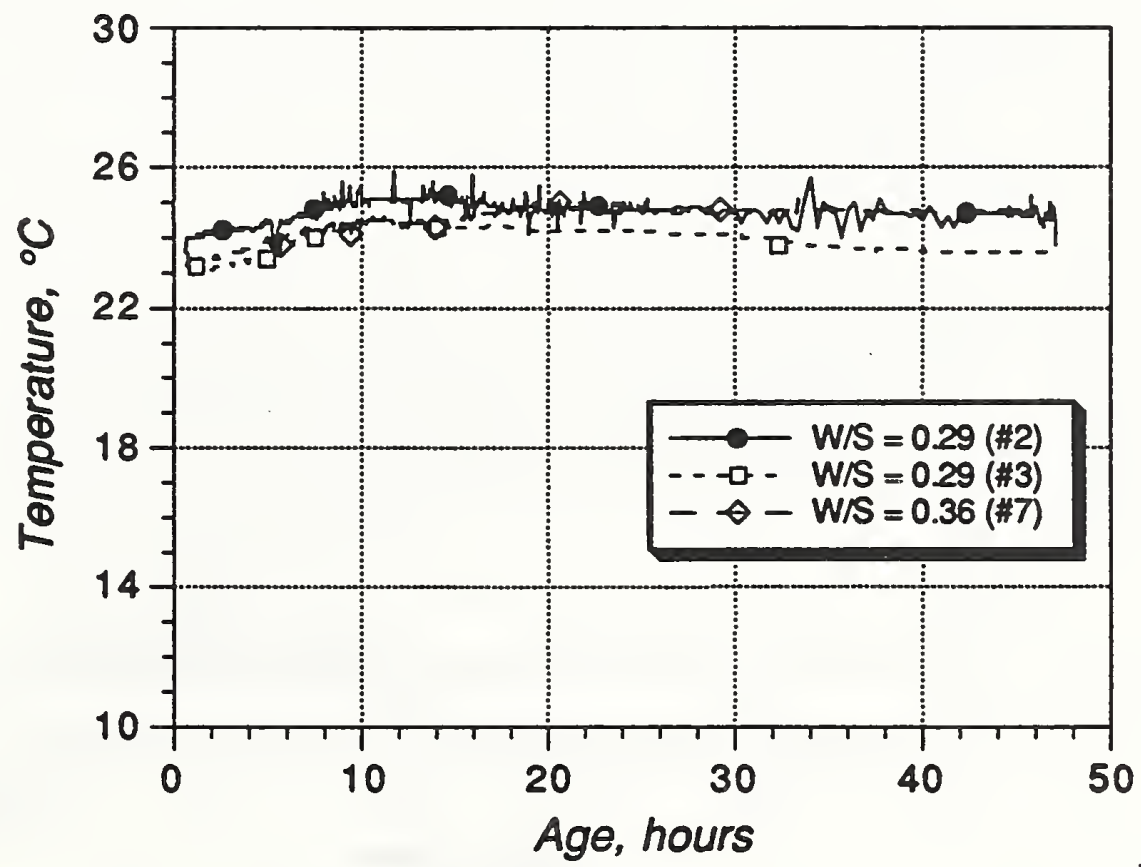

Figure A.2 Early-age temperature histories for cubes cured at $23^{\circ} \mathrm{C}$ 


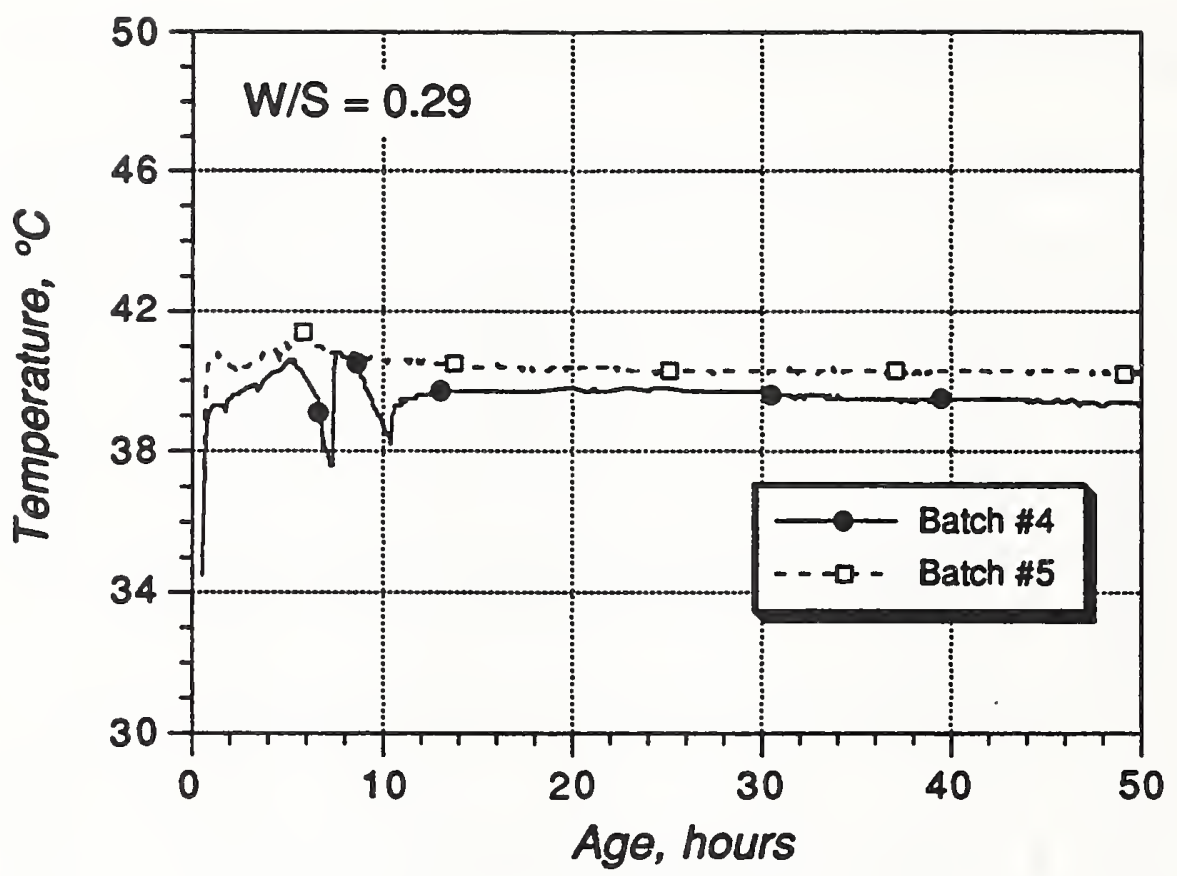

Figure A.3 Early-age temperature histories for cubes cured at $40^{\circ} \mathrm{C}$ for $\mathrm{W} / \mathrm{S}=0.29$

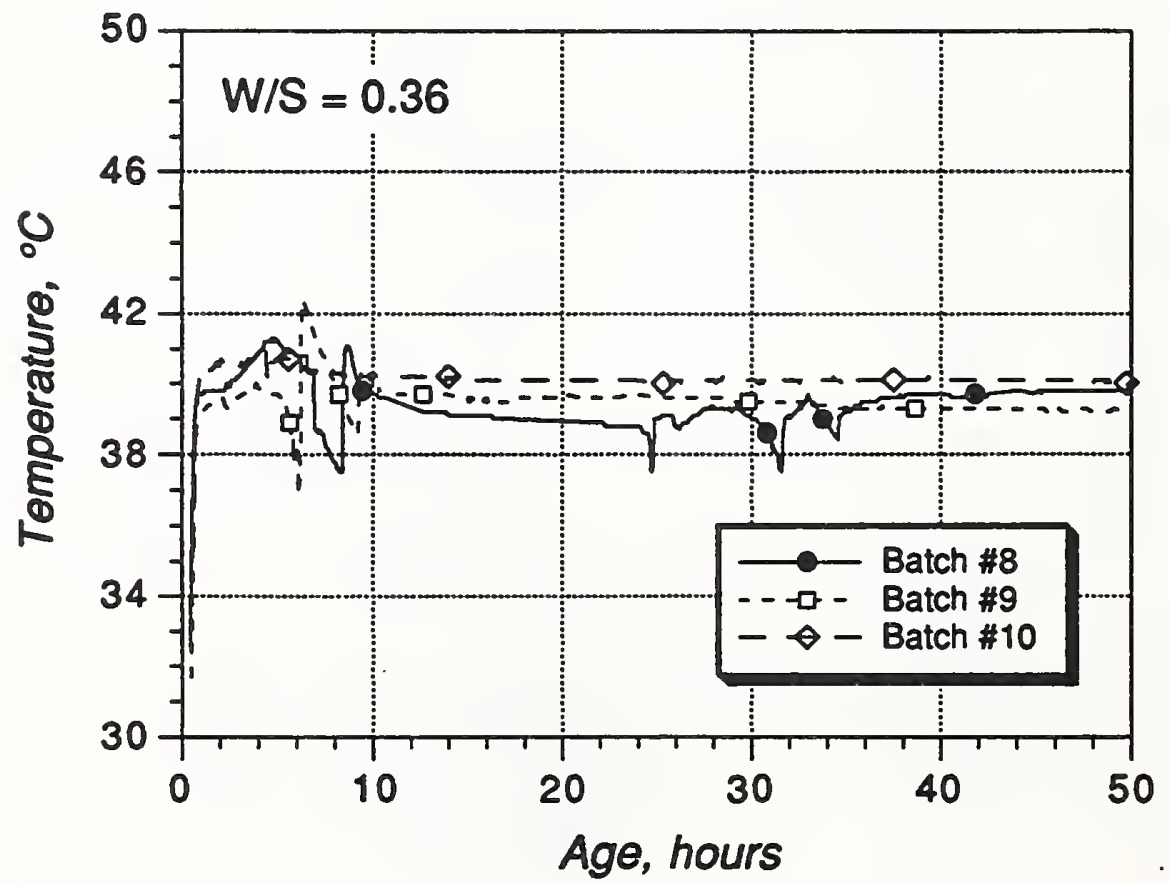

Figure A.4 Early-age temperature histories for cubes cured at $40^{\circ} \mathrm{C}$ for $\mathrm{W} / \mathrm{S}=0.36$ 


\section{BIBLIOGRAPHIC DATA SHEET}

2 PERFORMING ORGANIZATION REPORT NUMBER

4. TITLEAND SUBTITIE

Applicability of the Maturity Method to High-Performance Concrete

5. AUTHOR(S)

Nicholas J. Carino, Lawrence I. Knab, James R. Clifton

6. PERFORMING ORGANIZATION (IF JOINT OR OTHER THAN MIST, SEE INSTRUCTIONS)

U.S. DEPARTMENT OF COMMERCE

MATIONAL INSTITUTE OF STANDARDS AND TECHNOLOGY

GATTHERSBURG, MD 20899

7. CONTRACT/GRANT NUMBER

8. TYPE OF REPORT AND PERIOD COVERED

9. SPONSORING ORGANIZATION NAME AND COMPLETE ADDRESS (STREET, CITY, STATE, ZIP)
U.S. Department of Commerce
U.S. Dept of Transportation
Natl. Inst. of Stand. and Tech.
Gaithersburg, MD 20899
Office of Engrg. and Highway Ops.
Pavements Division
U.S. Army Corps of Engineers
Headquarters
Washington, DC 20590
Washington, DC 20314

10. SUPPLEMENTARY NOTES

11. ABSTRACT (A 200-WORD OR LESS FACTUAL SUMMARY OF MOST SIGNIFICANT INFORMATION. IF DOCUMENT INCLUDES A SIGNIFICANT BIBLOGRAPHY OR UTERATURE SURVEY, MENTION IT HERE.)

This study examines whether the maturity method is applicable to represent the strength development of highperformance concrete mixtures cured at different temperatures. Two mortar mixtures were investigated having water to cementitious solids ratios of 0.29 and 0.36 . The mixtures were made with Type I cement, silica fume ( $10 \%$ by mass of cement), and a high-range water reducing admixture. Ten batches of mortar were prepared to make cube specimens, which were cured under water at three temperatures: 7,23 , and $40^{\circ} \mathrm{C}$. Compression strengths were measured at ages ranging from 5 hours to 139 days. The strength-age data were analyzed using three models to determine the rate constant for strength development at each curing temperature. The models included two hyperbolic equations (linear and parabolic) and an exponential equation. The rate constant versus curing temperature relationship for each model was represented by a simple exponential equation, which was used to convert test ages to equivalent ages of curing at $23{ }^{\circ} \mathrm{C}$. The strength development of the various mortar batches could be described by a single equation relating relative strength to equivalent age. Thus it was concluded that the maturity method is applicable to describe strength development of the low water-cement ratio mixtures. It was also observed that the estimated long-term strength of the batches did not appear to be affected by the curing temperature. This is in direct contrast with the known behavior of conventional concrete mixtures.

12. KEY WORDS (6 TO 12 ENTRIES; ALPHABETICAL OADER; CAPITALZE ONLY PROPER NAMES; AND SEPARATE KEY WORDS BY SEMICOLONS)

Concrete, high-performance concrete, curing, maturity method, models, mortar, regression analysis, silica fume, strength, temperature.

\section{AVALABILTY}

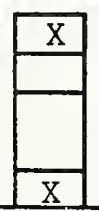

UNUMITED

FOR OFFICIAL DISTAIBUTION. DO NOT RELEASE TO NATHONAL TECHNICAL INFORMATION SERVCE (NTIS).

ORDER FROM SUPERINTENDENT OF DOCUMENTS, U.S. GOVERNMENT PRINTING OFFICE, WASHINGTON, DC 20402.

ORDER FROM NATIONAL TECHMICAL INFORMATION SEAVCE (NTIS), SPRIMGFIELD, VA 22161.

\begin{tabular}{|} 
14. NUMBEA OF PRINTED PAGES \\
$64-$ \\
\hline A04. PRICE \\
\end{tabular}



